\title{
RELATIONAL VERSUS RELATIONIST SOCIOLOGY: A NEW PARADIGM IN THE SOCIAL SCIENCES
}

\author{
Pierpaolo Donati \\ University of Bologna
}

\section{/// Introduction: What is Society? And What is a Social Fact? The "Relational Turn"}

Sociology is the science of society. But what is society? What is "the social" and how can it be examined scientifically? This contribution is intended to introduce the answers to these questions given by my relational sociology, which has been developed since 1983. In a nutshell, I will introduce my relational theory of society, which differs from other sociologies that are called "relational" but are in fact "figurational," "transactional," and/or in one way or another "reductionist" (I call them "relationist" instead of "relational," as I will explain below). I object to methodological individualism and methodological holism by proposing a relational methodology (not a methodological relationism).

From my point of view, relational sociology is a way of observing and thinking that starts from the assumption that the problems of society are generated by social relations and aims to understand, and if possible, solve them, not purely on the basis of individual or voluntary actions, nor conversely, purely through collective or structural ones, but via new social relations and a new articulation of these relations. The social is relational in essence. Social facts can be understood and explained by assuming that "in the beginning (of any social fact there) is the relation." No one can escape the complexity entailed in and by this approach, which aspires to advance a theory and method appropriate to a more complex order of reality. ${ }^{1}$

\footnotetext{
1 With regard to the meaning of the concepts of approaches, paradigm, theory and method I refer the reader to chapter 1 of Donati (1983). A further development of these concepts and their interdependencies can be found in Donati (2011).
} 
My relational sociology looks at reality from a perspective which is both specific and general — that of relationality. ${ }^{2}$ It is both descriptive-explicative and practical, sensitive to normativity, aimed neither at individuals nor at social structures as such, but at social relations-analysing, interpreting and attributing value to them as the precondition of problems arising and the means for their potential solution. To say "sensitive to normativity" does not mean ideological or directive (Hałas 2016). In my opinion, the sociologist must avoid any conflation between scientific research and whatever ethical or ideological imperative that may constrain it a priori. When we say that the sociologist has to do science with conscience, this does not mean that sociological research should necessarily be bound to a certain moral nor, of course, that it should take a moral stance of indifference. It must be impartial in the sense of respecting the objectivity of social events, but at the same time, it cannot refrain from pointing out that the social facts analysed have certain moral dimensions and lead to certain moral consequences instead of others, without thereby affecting the analysis with a priori personal ethical choices. In this way, professional sociology can take care of the value orientations that are at stake, for instance, in respect to human rights, without prejudice to scientific work (Brint 2005).

From the applied perspective, which is oriented towards network intervention, it is a question of producing a change that allows the subjects to manage their own significant, actual and potential relations. They do this by bringing their existing human and material resources-both manifest and latent-into play, so they can achieve an adequate level of selfregulation, or at least sufficient to confront their problems, which would otherwise be perceived and classified as problems of individual actors or of abstract collective entities alone.

Relational sociology does not come from nowhere, nor is it determined a priori by a "closed" (self-referential) theory. Historically it presupposes the emergence of a particular form of society that I call "relational society" (Donati 2011: 56-58). In its very mode of being, this society emerges from the phenomena of globalization. It has, as its guiding principle (or motor, if you like), the continual generation of social relations, through processes of differentiation, conflict and integration, both at the intersubjective level (in primary networks) and at a general level (in secondary, impersonal, and

\footnotetext{
2 The perspective is comprehensive in so far as social relations are spread throughout society, as society is made up of social relations, even though we observe such relations, from time to time, as economic, political, juridical, psychological and so on. And it is specific, in so far as the relation is observed not from a logical, economic, political or juridical standpoint, but from a social standpoint which implies it is imbued with meaning by the subjects who are mutually involved.
} 
organisational networks). Such a society calls for a theoretical and applied vision of social reality sufficiently open to itself and about itself to think relationally in a reflexive mode. ${ }^{3}$

In this contribution I present a general outline of this approach in the belief that only a theory with its own specific and widely applicable defining principles can provide the understanding and pragmatic application appropriate to giving sociology its practical character.

The main difficulty encountered is that of distinguishing this approach from other approaches called "relational," which lay greatest emphasis on the role of relations, but in fact have a reductionist understanding of social relations. I am referring in particular to many versions of functionalism (from Talcott Parsons to Niklas Luhmann), most structuralist conceptions of social networks (as we find in the works of Ronald Burt, Barry Wellman and others), and the relativistic reading of social relations made by neo-pragmatist sociologists (such as Mustafa Emirbayer 1997, François Dépelteau \& Chris Powell 2013), who, properly speaking, propose not a relational but a "transactional" sociology.

My approach relies upon a kind of realism that I name analytical, critical and relational, in a word "relational realism" (Donati 1983: 10; further developed in Donati 2011: 97-119). It is intended to be an alternative to those relational approaches that are founded on a constructionist (flat) ontology, but it is not an attempt to unify all sociological approaches around the notion of relationship as a replacement category of other categories (such as system or network). From the very start, I conceived of my relational sociology as a general framework to connect the best of all other theories and not as a reductio ad unum (Donati 1983: 11-12). I do not agree with those scholars who, in order to avoid a unifying theory, propose a "plural relational sociology." While I agree that we must avoid a unifying theory, which would be constrictive and restrictive, I do not think we need to call relational sociology "plural," given that, if the theory is truly relational, then it should necessarily be pluralistic, provided that it can understand and cope with the essential property of the relation, which is to join the terms that it connects while at the same time promoting their differences (what I have called the "enigma" of the relation: Donati 2015). It is precisely the absence or rejection of the relation that undermines pluralism.

In my view, in order to be really relational, the first move is to assume the social relation as the basic unit of analysis. This does not mean replacing the concept of the individual or the system with that of the rela-

3 On reflexivity see Archer (2012). 
tion. On the contrary, this move is useful for better elucidating what is an individual and a system from the sociological viewpoint. What I am saying is that sociology should observe, think of, and act on the social not as an expression of a system (as methodological holism does), nor as the expression or product of individual action (as methodological individualism does) but as an expression of the relationality generated by human beings. As I will explain below, my approach retains within itself the relevance of the human perspective in a particular way, i.e., by considering the fact that society is made by human beings, but does not consist of human beings. It consists of relationships. ${ }^{4}$

To say that the social relation has a reality of its own not only distinguishes it from systems and action theories, without having to take sides with either of them but, above all, enables us to see in social relations a reality which, although invisible, unspoken, and often uncertain, constitutes the substratum on which society is built and changed, both in its origins and in its search for human solutions to "social problems"- - contrary to what is argued by constructionism. In particular I argue against those relational sociologies that reduce social relations to pure communications, and therefore believe that social relations can be built in any way (as Luhmann 1995 maintains). To my mind, relations are certainly contingent, but this does not mean that they can be "always otherwise" as relationists believe.

In short, relational sociology is predicated on the "relational turn" in society, which was effected by modernity but goes beyond it. It carries forward that relational vision of society first stated but only initially explored and interpreted by Marx, Weber, and Simmel, by developing beyond these authors an integral relational theory of society articulated into a sui generis ontology, epistemology, methodology resulting in a peculiar social practice.

\section{/// The Ontological Premises of "Relational Thinking"}

The emergence of what I call "relational society" is a historical process which embodies and produces a paradigm shift from the simple to the complex. This process can and should be represented as a radical change in the ontological, epistemological, and phenomenological status of social

\footnotetext{
4 In other words, it maintains a humanistic concern, one, however that is no longer understood in classical terms (as the coincidence of the social and human, by which the social was understood as immediately human) but as emergent processes of differentiation of the social from the human (see Donati 2009).
} 
relations in both science and society. To understand this transformation we must furnish ourselves with an approach that (a) enables us to grasp the reality of social relations on their own terms, and (b) that succeeds in defining the object of analysis and of intervention as social relations. These points need to be discussed in more detail. Through them we enter the realm of "relational thinking."

\section{Social Relations Are "Real" on Their Own Terms}

To say that social relations have a reality of their own means that they are not a simple derivative of something else, but constitute a proper order of reality with its own internal strata, each of which requires particular attention and theoretical and practical treatment. In its turn, this order of reality cannot be reduced to this or that particular factor or variable (such as power or economic utility), because it is the relationality that is the social. Just as in the organic system, a human person cannot exist without oxygen and food, while not being reducible to either, so in the social system, human beings cannot exist without relations with each other. These relations are constitutive of the possibility of being a person, just as oxygen and food are for the body. If one were to suspend the relation with the other, one would suspend the relation with the self. The social sciences are concerned with this and nothing else.

There are two levels on which sociological observation can be placed:

a) On the first, most elementary level, relations are observed but they are analysed by looking at one factor or variable (so to speak, for example one of the generalized means of exchange such as money, power, or influence, etc.) that runs from A to B and vice versa, in social exchanges;

b) On the second, reflexive level, what is to be observed are not the single factors within the relation but rather the reality (the dynamic structure) of the relations as such; as a matter of fact, once relations have been brought into stable existence, they have their own autonomy, so that concrete entities, such as the historical products of society, including institutions, can be observed and interpreted as relational networks stemming from a relationally contested social context.

Certainly we do not see social relations wandering about, so to speak. However, we know that they exist, not only because they materialize in forms, movements, and social institutions, but because we have experience 
of them. That they are of a contingent order is not a good reason for saying that they have no reality: eye-colour, for example, is a contingent characteristic but is nevertheless a reality.

What, therefore, is this reality? It is the reality of a relation between us and things, between ourselves and others, that is not a logical relation, nor a merely psychic one. A social relation is distinguished from logical and/or psychic relations in that it:

a) refers, i.e., makes symbolic references (refero);

b) connects or structurally binds (religo);

c) and in being an emergent stemming from the reciprocal action (in Italian rel-azione, in French rel-ations) of mutual interaction. ${ }^{5}$

In order to observe social relations, the researcher needs a theory of the observer who observes as a third party ${ }^{6}$ and an appropriate methodology (for example the AGIL paradigm as it will be illustrated in its relational version below). The social is a relational matter, not a projection of individuals or a holistic entity, which lies in between the actors, as well as in between the observer and the observed. In contrast to the physical field, in which the relations between material entities are mechanistic, in the social field, the relationship is communicative and interpretive. Social feedbacks are relational, not mechanical (Donati 2013).

Therefore, in adopting the relational perspective, the first assumption is that the observer should situate himself at an invisible but nonetheless real level of reality, for which the relation is a third element. It must always be situated in this frame of reference if one is to avoid epistemic relativity from being transformed into relativism. However hard it is to grasp, relationality exists not only at the social level, but also in the interconnections between the other levels of reality-biological, psychic, ethical, political, and economic.

\footnotetext{
5 This is the meaning of the concept of Wechselwirkung ("effect of reciprocity") put forward by G. Simmel.

6 To gain a clearer idea of the sense and place of the relation in the theory of self-referential observation, it is worth citing von Foerster: "According to the 'Principle of Relativity' that rejects a hypothesis when it does not hold for two instances simultaneously (e.g., the inhabitants of Earth and Venus can both be coherent in affirming that they are the centre of the universe, but their claims fall apart when they are both found making them) the solipsistic affirmation collapses when I find another autonomous organism beyond myself. Therefore, one must note that since the Principle of Relativity is not a logical necessity nor a principle that can be proved as true or false, the crucial point is that I am free to choose to adopt or reject this principle. If I reject it, I am the centre of the universe, my dreams and nightmares are my reality, my language is a monologue, and my logic is monologic. If I adopt it, neither I, nor the other, can be the centre of the universe. As in a heliocentric universe, there must be a third element that is the central reference point. It is the relation You and I, and this relation (i.e., social reality) = community" (1984: 307-308).
} 


\section{The Social Relation Defines the Object of Sociological Research}

The relation is not only a medium of knowledge or a logical concept. It is the viewpoint from which whoever wants to do a sociological analysis, interpret data, or deal with practical social issues, must define his objects. If the social nature of phenomena is to be captured, every social object can, or rather should, be defined in relational terms. Usually I contest the concept that sociology studies "relations among social facts," but rather insist that it studies "social facts as relations." Society is—not "has"- - relations. It is not a field or a space where relations "happen." In saying this, I claim that the objects of sociology, and therefore its concepts, must first of all be redefined as relations.

At the start of a research project, when we pose the problem ("How and why does $Y$ happen?" with $Y$ being a phenomenon without an evident and intuitive explanation) we can never forget that the object of study which grows out of a situation (the $Y$ phenomenon) is immersed in a relational context and gives birth to another relational context. The major error of Husserl's phenomenological approach is to think of social relations as a synonym of mere inter-subjectivity, i.e., as an expression of empathy or sharing of values. A critical realist view of social relations is distinguished from the phenomenological one which sees social relations as an afterthought, emanating from the operations of transcendental consciousness or ego. The Husserlian idea according to which the social relation should be put into brackets (the procedure called epoché) and subsequently found as an expression of the transcendental Ego is self-defeating (Toulemont 1962). On the contrary, I claim that relational sociology should maintain that the social relation is the starting point of sociological analysis ("in the beginning is the relation") and the key way of getting to know the subjects and objects, and not the other way round. Elsewhere I have tried to give some examples of this procedure, applying it to such topics as education, social capital, health, family, chronic illness, citizenship, the welfare state, and social policy (for a general overview of these empirical studies see Terenzi et al. 2016).

\section{Relationality in the Social Sphere Entails a Symbolic Code of Its Own}

In seeking to understand and explain social reality, it is important to make clear the specific symbolic code that is being used or referred to, with 
regard to the kind and degree of relationality that it entails. For example, I maintain that binary codes (yes-no, 0-1, inside-outside, etc.) present the most simplified kind and degree of relationality.

To cite one case, the binary code used by Luhmann, although useful in certain respects, is only superficially capable of capturing the relationality of the complex interactive systems to which it is applied. In reality, the binary code is derived from the primacy of the economic sub-system (with its own functional code of efficiency) and from the logic of competition which is a relational form that is not properly interactive. This helps to explain why Luhmann's sociology is so resistant to dealing with concrete social relations. In truth, the binary code is valid only for certain phenomena, of a more logical, biological, or even psychic, rather than sociological kind. For example, one cannot treat the phenomenology of relations between public and private without introducing simplifications that are not appropriate to the object of study. In any case, such reductionism is incompatible with a discipline that does not, and cannot, deal with all social phenomena as if they were binary functions, since many social facts do not fall on one side or the other.

To define an object in relational terms, sociology needs codes of greater complexity than the reductive selection effected by either/or binary codes. Appropriate symbolic codes and models of analysis are required. A "symbolic code" is needed that does not look solely at the relata (that which is related) but at the relations themselves, as mediations not reducible to their components. Empirical studies of relations have demonstrated exactly this. The relation is made up of diverse contributions which can be distinguished as follows: the effect of ego on alter (the elements brought by ego towards alter), the effect of alter on ego (the responsiveness of alter to ego), and the effect of their interaction (the combination of the elements brought by alter ego and operated through the dynamics of the relational structure) (see Cook \& Dreyer 1984; Tam 1989). These effects can be observed and measured, given suitable methods. The first two effects can be analysed at the level of the individual, the third can only be observed by taking the relation as the unit of analysis. On the other hand, if one carries out the sociological analysis in terms of system theory, since every system is part of a broader system, what happens is that the level of analysis that is chosen is always incomplete (Luhmann 1995). Every system must be defined in relation to the higher order system, but a supreme system of all systems, to which final appeal can be made, does not exist. In this way, the autonomy of every actor/agent, which is always relative (that is, consists in 
a given complex of relation in respect to other autonomies within a context), is dissolved. As Richard Rorty (1999: 54) puts it: "Everything that can serve as a term of relation can be dissolved into another set of relations, and so on forever."

\section{Social Relations Entail Network Patterns That Do Not Eliminate Subjectivity or the Importance of Individual Elements, Although Transforming Them}

Network models that reveal the contribution of individual components in interactions, just as much as the resultant effects, are required for social analysis and intervention. In this light, social systems appear as "condensates of social networks" (Donati 1991: chap. 2).

The empirical study of relations allows us to distinguish the contribution of individual subjects from their social conditioning as such. To echo Tam (1989), interdependence is not a circular idea. If the central importance of the elements in a social network is due to their mutual interdependence, how can we claim that part of this is autonomously generated by an individual element, i.e., that it is due to characteristics of the element itself rather than to the relation with others? The reply is that, even if we adopt a vision of the world in which each individual depends on every other, we can still meaningfully separate what it is about the component that is self-generated from that which is derived from the other. In other words, the borderline between an ego and its social context can be drawn quite precisely even in a social system. A fundamental premise of relational sociology does not imply that the Self is lost in the midst of social interdependence. ${ }^{7}$

Therefore, the logic of networks is based neither on the negation of the subject, nor on the circular logic of phenomenology. It is rather the path of observing, describing, and defining the identity of every social actor by taking into account each one's subjectivity while avoiding an indeterminate circularity that goes on ad infinitum. To put it in terms of social ontology, substance (nature, structure) and relation (relationality) are co-principles of

\footnotetext{
As May Sim (2003) rightly points out, habituation into virtue, social relations, and paradigmatic persons are central for both Aristotle and Confucius. Both therefore need a notion of self to support them. But: Aristotle's individualistic metaphysics cannot account for the thick relations that this requires, and the Confucian self, if entirely relationistic, cannot function as a locus of choice and agency; if fully ritualistic, it cannot function as a source of moral norms that might help assess existing social properties. It is here where my relational approach comes into play, in order to correct both perspectives.
} 
social reality. For critical realists, "it is the nature of objects that determines their cognitive possibilities for us" (Bhaskar 1979: 31). Thus, it is the object under investigation and our research questions that determine which method is appropriate to use and why.

As Buch-Hansen (2013) has argued, in the field of social network analysis (SNA) there is a tension between applied and methods-oriented SNA studies, on the one hand, and those addressing the social-theoretical nature and implications of networks on the other. The former, in many cases, exhibits positivist tendencies, whereas the latter incorporate a number of assumptions that are directly compatible with core critical realist views on the nature of social reality and knowledge. I agree with this author in suggesting that SNA could be detached from positivist social science and come to constitute a valuable instrument in the critical realist toolbox.

\section{Relationality Is Not Relativism but Specific Determinacy}

The contemporary social sciences are for the most part relativist, understanding social relations as a way of dissolving the substantive and singular nature of both consciousness and social phenomena. In contrast, I understand the relational approach as a means of distancing oneself from relativism. The most that the currently dominant, relativistic sociological approaches can concede to a non-relativistic position is one or other of the following. Either empirically verifiable "sets of values" exist which are culturally transmitted and constrain possibilities, or interactively established norms exist which generate a procedural rationality that makes selfrestraint possible. Self-restraints are generally thought of as the production of Eigenvalues (values self-produced by the reiteration of communications) or "natural drifts." the "persistence (or reproduction) of values" comes to be seen and labelled as a mere survival of backward cultural orientations.

However, both these solutions have very little that is sociological or relational about them and they do not appear very satisfactory: the former appeals to imposed values (echoing the Durkheimian contrainte sociale), the latter falls back on spontaneous origins. The former has to appeal to a notion of cultural traditions that brings with it many deficiencies that seriously limit its explanatory force. The latter reduces normativity to a purely

8 On the theory of "natural drift" (put forward by H. Maturana and F. Varela) see Etxeberria (2004). 
evolutionary interactive affair. In either case, it is not clear how to avoid appealing to normative as opposed to random solutions.

Resorting to a multidimensional schema as Alexander (1996) does can be useful in avoiding the pitfalls of reductionism and conflation. However, multidimensionality is not an adequate approach to solve the problems of indeterminacy when sociological analysis must cope with the issues of the origins and consistency of the "standard values" (or "symbols," as invoked by Alexander) that are supposed to break the circularity of the multiplicity of the variables involved in the social processes. Social institutions would simply be the outcome of what a culture has, through a myriad of repeated operations and reiterated interactions produced and eventually applied to such institutions themselves. Those who have rejected this type of relativist formulation have looked for structural laws-as did most of nineteenthcentury sociology. But the very same modern, and now contemporary, society, is bent on their denial.

Where, then, is the break in this circularity to be found? Perhaps in the structure of a presupposed a priori reality? To my mind, even this answer is sociologically implausible since what makes a social institution (or social relation) is not that it fits into a posited pre-existing structure, as symbolic representation does.

To me, the answer seems to be both simple and complex at the same time: it is rooted in the demands of the relation itself in so far as it is enacted by the subjects who institute it as a determinate relation endowed with its own structure. I am not saying either that the relation is produced by the agents' mere intentionality or that the relation is a product of mechanical operations. What I am saying is that the determination of the relational structure is the result of a combination of subjective and objective factors that does not correspond to both subjective and objective factors: it is a creation which responds to the "enigma" of the relation which consists in its capacity to unite while differentiating its terms at the same time (Donati 2015). The relation between an employer and worker, or doctor and patient is not the same, for instance, as a couple's relationship. In responding to these specific demands, there is restricted room for indeterminacy and going back further and further in the causal chain necessarily has its limits. The circularity is broken by the relation itself when it is taken for what it is, as that relation and not as something else, that is, when it is redefined according to its own distinctive character of having to unite two terms within a definite scope. It is an accomplishment of the task of building a We-relation between different agents/actors. 


\section{/// An Example}

An example could perhaps help to clarify what is being stated here. It is the problem that is often raised of knowing what the social reality of the family is.

In a certain sense, sociology has lost its way by having adopted many analogies of a spatial, biological, organic, cybernetic-informational, or other kind, or rather taken the family as a place, niche, cell, self-regulated system, and so forth. Today it no longer seems to know what the "family" is. There is a great temptation to subsume it as a generic kind of primary group, despite the existence of a body of theoretical and empirical research that has, for quite a while, made clear that the family cannot be subsumed as a generic form of human co-habitation or as a mere informal primary group missing its own differentiation.

From a relational perspective, if the family were only a communicative arrangement that enables "the orientation of the person to the whole person," as Luhmann maintains (1988: 75-76), it is not evident why this is so and why it is the only social system (supposed to be of "pure interaction") to have such a function. We need a much deeper explanation. If the family is so, this happens because the family, as a specific social relation, has a suigeneris structure with its own symbolic code that enables it to maintain certain relations between the genders and generations. Certainly, I do not doubt that the family has a specific function in enabling personal orientation (or better: the orientation of communication to the individual as a person, i.e., as an individual-in-relation and not as an atom). But one should be very careful in maintaining, firstly, that such a function is exclusive to the family, and secondly, that the family in practice has only that function. The more general question that lies behind this difficult issue is whether the family can be considered the unique social sphere from which a peculiar generalized symbolic medium of interchange stems - be it called trust, reciprocity, or solidarity- that can circulate in the whole societal system, or not. ${ }^{9}$

It is only possible to get away from the current disarray in sociology about what the family is by grasping the autonomous reality of this relation on its own terms. But of what does the "relational reality" of the family

\footnotetext{
9 Luhmann is ambivalent in this regard. The early Luhmann maintained, with Parsons, that love was the generalized symbolic medium of exchange belonging to the family, but in later writings this aspect seems to fade away. Love as passion is certainly not a medium that can circulate in the social system as a recognisable and practicable means used by other sub-systems. In reality, with the communicative turn, Luhmann gives quite another meaning to symbolic media than they had in Parsonian theory. Whether and how such a medium can be understood as reciprocity is an open question.
} 
consist? Perhaps we see "the family" go for a walk? Certainly not. Let us suppose, however banal the example may be, we see a man, a woman, and a child walking in a park. If we already know them as the White family, we will say that is the White family walking there. If we do not know them, we will think of a certain, finite number of possibilities of intersecting biological, psychic, and social relations between the people at whom we are looking: the judgement on whether or not this is a family cannot be decided and is suspended. So, what is "the" family that we can observe? Suppose that another sibling or the granny or another person normally resident under the same roof were missing, what would we say? In reality, we see individuals, but we think through/with relations. In order to say that this is a family or not we have to ascertain what kind of relations exist between the people we observe. Only if we know or presume certain relations between them, do we say that that is the White family which, wholly or in part-is going for a walk. Therefore, the presupposition is the existence of a certain relation that connects the elements we observe. We see individuals but we speak on the supposition of relations. The word "family" indicates relations. The members of the family can be there or not, but all the language that we adopt to describe what we see beyond single individuals is essentially that of relations. The words make sense only if they refer back to relations.

However, this still does not tell us what that relation consists of which we call "family" and attribute to the group of people $X$ whom we see. In the first instance, it consists of the fact that the terms symbolically linked through observation are "something" standing for something else. This something is not fixed forever, but is necessary if one wishes there to be, as indeed there is, a relation (if it is not of kinship, it will be of another kind, but this does not prevent us from having to ask ourselves what it could be). One wonders: is this "something" only a subjective interpretation, or even, is it an objectified reality established merely through inter-subjective agreement?

Certainly, I, who see the White family going for a walk, "interpret" it through symbols - signs that stand for something else-in relation to a meaning. This interpretive act is rather complex, as it involves perceptions, image-making and specific evaluations, all acts which are not simple in themselves. But the point is the following: is it "I" (my Self) who attribute meaning to the relation that I call the White family, or is it "We"I as observer in interpersonal relation with others, including the observed subjects-who define the group before us as a family? 
It seems to me that the answer is neither. The meaning is never a private subjective conclusion, nor solely an intersubjective one. The meaning is the work of a whole culture. In its turn, "the family" is precisely a complex tissue (many condensed linkages) of relations that refer back in turn to other symbols, lived experiences, and the like, which are not purely subjective or intersubjective. In saying that "I see the White family going for a walk" I am referring to something that goes beyond myself and the subjects present in that situation. The reference (that which is signified) is to the social structure that actualizes the complicated tissue of relations between culture, personality, social norms, and possibly biological premises. Such an interwoven tissue certainly changes historically, but it is not purely subjective or intersubjective.

Therefore, the relation that I call "family" is not only the product of perceptions, sentiments, and intersubjective mental states more or less empathetic with others, but is both a symbolic fact ("a reference to") and a structural fact ("a bond between") which, combined together, generate an emergent: the family as a "We-relation" or a "Relational Subject" (Donati \& Archer 2015). As such, it cannot be reduced to the individual subjects (their expectations, representations, ideas, perceptions, etc.) even though it can only come alive through these subjects. It is in them that the relation takes on a peculiar life of its own, but the individualization of the bodily and mental processes of perception, sensation, and imagination, even where creativity is involved, cannot come about except through what we share with others. This is what is meant by the claim that every social relation entails a cultural model in which symbols are embedded (see Hałas 1991). After all, a cultural model means a symbolic reference which feeds those feelings, sentiments, and emotions that motivate people to enter and stay in a relationship or avoid it and get out. As Fuhse (2009) rightly points out, it is necessary to conceptualize and to study social networks in conjunction with culture for many reasons. First, because social networks function as the habitat of cultural forms: symbolic forms and styles diffuse in social networks, and they meet and combine at network intersections to form new styles and creativity. Second, because social networks are imprinted with culture; social categories and cultural models for relationships make for a particular ordering of network structure, rather than merely resulting from it. These two points constitute the interplay of culture and network structure: cultural forms are as much formed by networks as they shape them. Third, because networks themselves are not devoid of cultural meaning: relationships build on cultural models like friendship or kinship. 
And the identities of the actors involved are constructed in dynamic processes of attribution and negotiation within the network. Thus, structure and culture do not form independent layers of the social but can only be distinguished analytically.

The interweaving of relations that make up a relation is infinitely open: however, that risks leading repeatedly to indeterminacy. Postmodern sociology is not characterized so much by having discovered this fact, as having accepted the challenge of understanding and constructing the social (e.g., the family and its internal social networks) on the basis of this indeterminacy.

So, is the family - in so far as it is a social relation - indeterminate? Or rather as a social relation can it refer back, in a purely contingent way, to other, ever more differentiated relations ad infinitum, according to a circular chain of determinants that are just reciprocal interactions? All experience counteracts this conclusion. From the reflexive point of view, if the relation is a complex tissue, there must be mechanisms of determination and their operations that are not purely interactive and circular ad infinitum.

But where are these mechanisms and how do these determinants operate? 'This is where the Achilles' heel of modern and postmodern paradigms is to be found. To modernist and postmodernist eyes, every break in the circularity that comes from outside the interaction seems dogmatic or responding to outdated ways of thinking of the "old Europe," as Luhmann calls it. As a result, they fall back on notions of Eigenvalues (self-generated values) to claim that the break in relational circularity takes place within the interactive process which itself establishes a self-generated value that functions as a provisional regulative norm in the interaction, by providing more trust than constraints.

Neo-functionalism insists on the idea that the very strong process of individualization within and between families, realized through the mechanism of re-entry that allows actors to escape its constraints without suppressing or eliminating them, does not allow us to conceptualize the family as a structured relation/interaction, and consequently, to think of the totality of families as a societal sub-system (in the same sense as we speak of the totality of the corporations as an economic sub-system)..$^{10}$

10 "There are only individual families and there is neither an organisation nor a medium (love) that unifies the numerous families. Neither are there, in contrast to segmented societies, institutions that enable a plurality of families to operate, at least under determinate conditions, as a unity" (Luhmann 1988: 89). 
The individualization of the family, according to Luhmann, is such as to justify the assertion that the totality of families has no social function as a totality and that families no longer share common cultural patterns, nor a specific medium of communication (love, solidarity), nor are capable of producing them. This contrasts totally with the reality of phenomena, as sociological research on the field has demonstrated in complex societies too, and not only in less functionally differentiated societies.

\section{/// The New (Critical Realist) Relational Approach}

By relying upon the above realist ontology, the solution to the aforesaid problems (of situating oneself at the level of the autonomous reality of social relations and defining the object in relational terms) entails an epistemological shift with a matching paradigm and methodology that, together, lead to the adoption of a sui generis practice in social work.

\section{Relational Epistemology}

The general supposition of sociological thinking could be summed up symbolically as: in the beginning there is the relation. Such a supposition must be understood in the realist, non-relativist sense. Being a possible object of human knowledge belongs to the nature of the real. There is no absolute separation between objective reality and the human intellect. When we turn our gaze onto the world of things, a prior and preceding relationship already exists.

The social process with all its distinctive features proceeds by, from, and through relations. This is what can be said in advance about social reality (phenomenology) just as about theory (from observation of, and reflection on it). Being relational is inherent to the make-up of social reality, just as of thought. It proceeds from relatively autonomous theoretical aspects, including intermediate, methodological ones, to empirical facts and back, in a continuous reflexive process between different passages and phases. By bringing the relation as a general, primary supposition into the metaphysical realm of knowledge, in no way assumes the absolute contingency of the social world-any more than it implies welcoming some ontology that denies the subject. On the contrary, it means assuming that the relation has a non-contingent root (or referent, if one prefers), that takes concrete form in contingent situations. Obviously such a root or referent 
stands outside the here and now of any given society, beyond concrete social phenomenology.

From the sociological point of view, only the relation itself is necessary, while the way it is actualized reflects the effective contingency of the social world which is "how it is" but could also be "different." It could be, but it is not. If it is how it is, it is like that because the relation, while necessary in itself, also necessitates historically specific determinants, which however, outside of our system of reference, are themselves contingent (Morandi 2010, 2011).

In this sense one can say, for example, that the primary forms of social life, in so far as they are social relations, exceed society. In that sense, they overtake or go beyond it in so far as they are not mere contingency (e.g., of a communicative kind). Let us think of the relationality involved in the family as a primary social group and its quality of exceeding society. To claim that the family exceeds society does not mean, as Luhmann maintains, that the family empirically has the greatest "density of communication" that can be detected among all forms of interaction. There can well be other social forms where such density can take place. From the relational sociology standpoint, the family exceeds society because it represents the need (necessity) for a full relationality that urges more and more complex (contingent) forms of arrangements in everyday life. ${ }^{11}$

\section{The Network Paradigm}

In this approach, society is understood according to a paradigm that is neither that of the whole and the part, nor of system/environment, nor autopoiesis, but that of a network. Society is understood as a network of relations, and, more precisely, not only relations between nodes, but also relations between relations. That is why, for instance, if we want to explain the dynamics of a family of three people as a social network we have to look not only at the networks of the three relations between the three

\footnotetext{
${ }_{11}$ The following statement by Huston and Robins helps us understand the concept of "full" relationality: "the reasons why relations function in the way that they do cannot be understood separately from their ecological context, a context which has historical, economic, cultural and physical components. Neither the psychological nor biological characteristics of participants can be ignored" (1982: 923). It is obvious that both theoretical and empirical research must be selective to carry out specific analyses. But one must be aware of the reductions of reality made by the scientific observer. And one should always bear in mind the fact that the more abstract the premise, the more likely that it is self-validating. In my view, the term "fully relational" shares something with what Clifford Geertz (1973) means by "thick description"- that is, the plurality of levels of discourse, the multidimensionality and inexhaustibility of their meanings.
} 
nodes, but we have to take into consideration a network of nine relations of the first, second, and third order. The more we increase the number of nodes, the more they increase dramatically the number of relations up to the third order, according to the formula (lambda function):

$$
\sum_{1}^{k} \mathrm{~F}_{k}\left(n_{k}\right)
$$

where $\mathrm{F}_{k}$ is the number of relations of $k$ order; $n=$ number of initial nodes $\geq 2$; $n_{k}=\mathrm{F}_{k-1}\left(n_{k-1}\right) ; \mathrm{F}_{1}\left(n_{1}\right)=n(n-1) / 2 .^{12}$

It is important to understand the relationship between the concept of a network and that of a system. The former is broader than the latter, not vice versa. Systems are a kind of condensation and stable self-organization of networks, as when a vapour or gas converts to a liquid and solidifies. Before becoming systems, social networks conduct (or are conductors of) a much richer reality and possibilities than we can see in terms of systemic characteristics. Here lies the rethinking, precisely in relational terms, of the current split between the structuralist and cultural (or communications) analysis of networks. Their difference lies in the different understanding of social differentiation, which is functional for the structuralists and relational for relational sociology. Simmel's sociology was a first insight into this difference if we compare his studies on the intersecting social circles (structural analysis) with his writings called fragments of everyday life (where he describes social reality as made of polymorphic and magmatic relations). Today, with the digitalization of everyday life, the phenomenon of social networks has acquired characteristics that require a relational paradigm much more sophisticated than in the past if we want to understand the complex logic of the new forms of networking.

\section{Relational Practice}

The practical implications of relational sociology can be categorized and organized under the approaches to social issues termed "network interventions."

12 For example: if $k=3$ and $n=3$, then $\Sigma_{k}(3)=9$; if $k=3$ and $n=4$, then $\Sigma_{k}(4)=126$. Suppose that we are studying a family: if we pass from a family of 3 members to a family of 4 members, the number of third order relations increases in such a way. 
The fundamental guidelines for such practices, as a support for social policy and social services, can be summarized as follows.

a) Isolated subjects and objects do not exist, but only complex interwoven relations in which subjects and objects are defined relationally, in their capacity to reproduce or change their identities and act relationally; to talk about processes of morphostasis and morphogenesis does not imply relativism, as though everything can be read and modified at will. The problem of relativism is resolved by defining the relations between different systems of reference.

b) When one intervenes with regard to the subject or object involved in a social issue, one must operate on the interwoven relations in which the observed subject/object is embedded; the intervention should aim at bettering the personal and collective reflexivity of the actors acting in the targeted setting, by observing the network effects that the proposed intervention can entail.

c) To know that a relationality exists between the observer and the observed, between the actor and acted upon, which has an affinity with a circular hermeneutics, is not an impediment to the steering character of the intervention, given that the hermeneutic circle can be broken through the network dynamics, at least temporarily. ${ }^{13}$

Obviously, there are varying degrees to which all this can be taken into consideration, consciously known, operationalized, and implemented in practice. But it is important not to give legitimacy to selective, a priori reductionism.

\section{/// Relational Does Not Mean Systemic}

In reconstructing the history of the paradigms with which sociology has understood society, Luhmann (1995) speaks of three great paradigms of a systemic order.

a) The paradigm of the part and the whole, based on the organic analogy of the relationship between the body and its organs (e.g., Herbert Spencer).

b) The paradigm of system and environment, developed by the early theorists of the social system as the relation between institutionalized roles and everything that is not institutionalized (e.g., Talcott Parsons).

13 For more details see the ODG (relational "Observation-Diagnosis-Guidance") systems of social intervention in Donati (1991: 346-356). 
c) The paradigm of autopoiesis, according to which systems are constituted only on the basis of their own structures and operations (Humberto Maturana and Francisco Varela).

This is not the place to discuss the evolution of systems theory, and in particular, the ability of one paradigm to substitute for another. I will only say that even the latter autopoietic paradigm, if understood as a radical alternative, is no less problematic than the other two. While a systemic paradigm certainly can no longer be one which links the part to the whole in an organic way, it must nevertheless respond adequately to the problem of the relations between the parts and the whole which compose them, in a way that is other than organic. It remains to be seen whether, in what sense and to what degree, the other two systemic paradigms can satisfy this requirement for adequacy.

My hypothesis is that neither the paradigm of system/environment, nor that of autopoiesis satisfies the requirements of relational thought. The first, because it is a theory of local differentiation. Every system is based on the difference of system/environment at boundary points sensitive to that distinction ("sensitive spots"), but this does not say anything about the relations between the system and its environment. The second is inadequate for the same reason, i.e., because it is a theory of the internal workings of systems. Therefore, we arrive at the following question: does a paradigm exist which elucidates the relations between the system and its environment without without adhering to the logic neither organic nor self-referential? I propose to explore this possibility through the concept of a relational paradigm that conceives the boundaries between system and environment as a network of relations.

The first question to be posed in this line of inquiry is: are social networks, by which we understand society today, social systems?

There are those who think so. Thus we are in the presence of a structuralist and/or neo-functionalist conception (Blau 1982). Those who remain dissatisfied with one or the other explanation seek a theory of "open" systems which makes recourse to some kind of phenomenological framework that appeals to intersubjectivity and empathy (e.g., Ardigò 1988). But here we need to be clear. The metaphor of open systems can be useful for shedding light on the limitations and reductionism of the metaphor of closed systems of a self-referential and self-reproductive kind. However, it is not an acceptable solution if one does not fully take on board the net-like character of society. 
The social relation between two actors (whether individual or collective) A and B can only be understood in a reductive way as a "system" and/or part of a system, in an "environment," if by social system one understands a complex of positions or roles occupied or carried out by actors, who interact through their behaviour in the framework of regulating norms or other types of constraint that limit the range of actions allowed to each subject in relation to the others. The concept of social network goes far beyond this definition of a social system. As Laumann, Marsden, and Prensky state: "There is no sense in which social networks need correspond 'naturally' to social systems" (1983: 33). Certainly, there is no correspondence if one adopts the definition of a social system as a plurality of actors who interact on the basis of a common symbolic system. But even adopting a more structuralist definition, it is evident that constraints (regulations, norms) and interdependencies are only some of the features inherent in the production and reproduction of preferential relations typical of social networks.

In other words, the sociological concept of network includes that of system without being reducible to it. Viewed from the perspective of the network, the social system is (a) an analytical aspect of the network that (b) makes manifest its functional interdependencies and (c), at the nodes of connection and disjuncture, retrospectively stabilises the mechanisms and circuits through which the phenomenology of the social manifests itself. But the network is also the conductor, locus, and means by which other aspects and dimensions of the social come to life and are expressed. Society therefore appears as a formal and informal mix that requires a new observational paradigm.

Faced with the fact that the concept of a social system only captures certain of the so-called functional aspects of society, it is easy to feel let down. So someone seeks to generalize the concept of the system and thoughtfully differentiates the elements of it in order to understand the informal, non-functional aspects of communicative interdependence, the "communal," the "life-world," and so on. And thus, an open system is theorized, which is characterized by the self-selective, self-directed and selfregulated - rather than mechanical, organic or static — development of its parts, which operates in an environment according to a symbolic code of a higher-order, cybernetic kind (Buckley 1967; Maruyama 1963).

However, with such a solution, the aforementioned informal aspects are necessarily subsumed into the system. No matter how flexible the latter is made out to be, with contingent boundaries capable of dealing with 
"fuzzy sets" and even "drift," the systemic code remains just as dependent on a mechanistic - i.e., cybernetic — reading of the social. This suggests that the non-systemic attributes of social relations are not treated on their own terms, but forced back into the systemic code or transposed, in order to set them apart, to another, necessarily marginal plane — of the irrational, magical, mythical, or "metaphysical."

On the other hand, it is also evident that social networks are not the product of pure spontaneity or interpersonal contingency. They are identified with the paths over which the human individual is free to roam but, at the same time, is not sovereign, i.e., is not master of what she or he chooses to do.

A study of primary, or informal, social networks of everyday life offers an illuminating viewpoint for observing social relations, as it is neither system nor life-world but the constant, live-in the human sense-interpenetration of one with the other. Through this conceptual itinerary, which envelops the whole of contemporary sociological reflection, I believe one can arrive at a fourth paradigm.

Such a paradigm:

a) recognizes that the "systemic-normative coherence" of the first two systems paradigms (Durkheim's structure of the whole and the part, and Parsons's system/environment) cannot explain the advent of a morphogenic society (Archer 2014); contemporary society is intrinsically characterized by the loosening and fragmentation of social relations, with the ending of socialization through internalization of norms;

b) rejects autopoiesis as a closed model, while accepting the need to include self-referentiality in the observation of social phenomenology, though together with hetero-referentiality;

c) recognises that social actors do not and cannot move at random, but they behave along paths that are culturally conditioned;

d) interprets the new normative order of the morphogenic society as the coming up of social networks run by a situational logic of opportunities ("a relational logic of networks") which is, at one and the same time, strategic (cognitive and instrumentally-driven), communicative (expressive and dialogical), and normative (based on generalized values).

With these provisos, the concept of network demonstrates its capacity to constitute a sort of meta-symbolic code for the concept of system. This latter must be further generalized and differentiated reflexively. Only in 
this way can analysis grasp social networks as a simultaneously formal and informal reality.

\section{/// Overcoming Functionalism Through Relational Sociology}

If one really wants to enter the relational way of thinking that I am proposing here, it is necessary to see it as a critical departure from functionalist thought, in particular in the versions running from Durkheim to Luhmann via Parsons.

Throughout the twentieth century, functionalist analysis has been the background, the leitmotif and the paradigmatic infrastructure of theory and empirical research, in sociology and other social sciences. To Kingsley Davis (1959: 758), ${ }^{14}$ functionalist analysis simply describes "what any science does." To him it is erroneous to think of anything other than functionalist analysis. But to my mind just the opposite is true. The reductionism brought about by functionalism has become more and more evident. Let us recall the main phases through which it developed.

1. In the first stage of functionalism, Durkheim reduced social relations to "functions." Social entities were defined not according to their full reality, but in terms only of the functions they performed in and for society. These functions, seen as social roles corresponding to the division of labour, became synonymous with social relations. From the beginning, this conception of relationality was characterized in a positivistic manner. In his celebrated Rules of Sociological Method, Durkheim made certain basic assumptions.

a) He opposed and replaced the notion of function with that of purpose. Finalism had to be banished from sociology. In explaining the rules for the explanation of social facts, he affirms that

we use the word function in preference to end or goal precisely because social phenomena generally do not exist for the usefulness of the result they produce. We must determine whether there is a correspondence between the fact being considered and the

\footnotetext{
14 Davis argues that: "Several lines of analysis show that functionalism is not a special method within sociology or social anthropology. First, the definitions most commonly agreed upon make functionalism synonymous with sociological analysis, and make non-functionalism synonymous with either reductionist theories or pure description. Second, the issues raised with respect to functionalism, except insofar as they spring from the ambiguities of words like 'function,' are really the basic issues or questions of sociological theory. Third, historically the rise of functionalism represented a revolt against reductionist theories, anti-theoretical empiricism, and moralistic or ideological views under the name of sociology or social anthropology" (1959: 757).
} 
general needs of the social organism, and in what this correspondence consists, without seeking to know whether it was intentional or not. All such questions of intention are, moreover, too subjective to be dealt with (Durkheim 1982: 137).

The organic analogy had to act as guarantor of the (positive) objectivity of sociological analysis (Durkheim 1984). ${ }^{15}$

b) On this basis, sociological analysis should explain phenomena through two procedures: first, analysis should relate the parts of society to the whole and, second, relate every part to each other, both operations being carried out with respect to the specialized "functions" performed by the parts for the whole.

According to Kingsley Davis, non-functionalism always implies: (a) some sort of reductionism (such as psychologism-which traces the status of individual consciousness back to the social, or biologism-which reduces the social to genetic factors, or to economic and technological determinism, etc., working in the same way) or (b) a rough empiricism, involving nothing but a non-theoretical manipulation of data (whilst systemicfunctional analysis implies an interpretative model, not simply statistical relations or historical data). As Davis himself reminds us, physiology has been and remains the constant model of reference for more or less all functionalist authors (such as Radcliffe-Brown, Malinowski, Firth, and Merton, among others).

Apparently, scientific language can easily return to the functionalism of common sense: "[T] speak of the function of an institution for a society or for another institution in that society is a way of asking what the institution does within the system to which it is relevant" (Davis 1959: 771). ${ }^{16}$ Functionalism, in this first version, is the description and explanation of phenomena from the standpoint of a system of reasoning which presumably bars a relation to a corresponding system of nature. In the case of sociology, what is distinctive is the subject, namely-according to Davis-society.

What has become of understanding and where has interpretation gone? Functionalist analysis already shows itself creating great difficulties: not only has the human subject been expelled (along with their internalized

\footnotetext{
15 Later, Merton will say: "social function refers to observable objective consequences, and not to subjective dispositions (aims, motives, purposes)" (1968: 78).

${ }_{16}$ The example given is the following: "[I]f every time one establishes a relationship one has to say 'the function of such is to do such and such' the circumlocution becomes tiresome. Why not say simply that the heart pumps blood though the system?” (Davis 1959: 772).
} 
motives and past experiences), but culture is treated as something naturalistic. As is inevitable, society becomes mechanistic. If the moves mentioned above are followed through, the social relation would be reduced to a mere structure with culture appearing as a restricted set of options. These are problems and ambiguities that this first stage of functionalism did not manage to resolve. Although society is depicted as a cultural organism, it is studied as a natural organism in evolution. That generic ambiguity was never to be renounced.

2. The second stage of functionalism refers to Talcott Parsons's theory. With Parsons, functionalism follows in the structural tracks of Durkheim. However, because Parsons intended to incorporate Weber's stress upon intentional agency with the non-rational factors emphasized by Pareto (the famous supposed convergence between Durkheim, Weber, and Pareto on the theory of action), social theory should abandon any claim to be seeking or advancing exact scientific laws.

Parsons's functionalism, at least in its first phase, is characterized by not wishing to lose the human subject as a subject of action and, hence, by conferring greater degrees of freedom upon culture, as well as incorporating "latency" within it (referring to "ultimate values"). Given this, it would seem possible to assert that the relation could be redefined in a non-reductionist way. However, Parsons never took this step. In fact, retaining and upholding the subject and culture within sociological theory proved to be more and more difficult, if not impossible, for the functionalist tradition.

With the adoption of the systemic approach and its redefinition in a biological and, above all, cybernetic manner, functionalism landed on the shores of a more and more markedly structuralist and relationalist relationality. The system takes the place of the subject and culture is reduced to a sub-system.

In comparison with the naive and primitive functionalism of the nineteenth century, Parsons introduced a further relational turn: he effected the transition from the whole/parts paradigm to the system/environment paradigm. With this shift, the social relation became a link between statusroles and an interchange between the system and its environment. At the heart of the relation lay the system.

Social integration and system integration were no longer incorporated in the same theory, but, on the contrary, were opposed one to the other as if they were two almost incompatible theories. Consequently, the social relation was split into the inter-subjective dimension (social integration) and the functional dimension (system integration), which can only confront 
and limit each other. To a large extent, classical functionalists remained tied to these difficulties.

3. The third wave of functionalism refers to the work of Luhmann, who took the most important trajectory for dealing with classic functionalism (Parsonian) and its unresolved ambivalences. In carving this out he drew (radical) conclusions from what had characterized functionalism from the beginning.

The main thread of theoretical functionalism, the concept of the system, became the fundamental axiom that Luhmann used to redefine all other concepts in this theoretical approach. The system/environment difference, introduced by Parsons, was raised to the status of the defining feature of the whole theory, as the unity of the distinction between identity and difference. In so doing, he moved to the new functionalist paradigm, which in some ways was already implicit from the beginning: the selfreferential autopoietic paradigm.

It should be noted that a certain conception of the relation is found at the source of this change, as it had also been in the passage from Durkheim to Parsons. Now, "theory requires formal concepts established at the level of relating relations" (Luhmann 1995: 10). It was, indeed, unfortunate that Luhmann radicalised a formalistic conception of social relations such that they were treated as logic relations. The implication was that, as in logic, the relation had first of all to be referred to itself (it is assumed to be a primitive concept, and, as such, a self-referent construct instead of being understood as an emergent reality) and consequently treated. In particular this means that, following the Luhmannian sociology, social relations cannot be submitted to an empirical analysis, both explanatory and interpretative, which can view their elements or components and the interactions between them.

The passage from the system/environment paradigm to the new selfreferential one is precisely marked by a conception of the relation as causa sui (relation as the causal explanation of itself). ${ }^{17}$

\footnotetext{
17 According to Luhmann: "Relatively simple theoretical constructions were still possible within the context of system/environment theory. The theory could be interpreted, for example, as a mere extension of causal relations: you had to consider internal as well as external factors in all causal explanations; system and environment would come together in a kind of co-production. The theory of self-referential systems bypasses this causal model. It considers causality (as well as logical deduction and every kind of asymmetrization) as a sort of organization of self-reference, and it 'explains' the difference between system and environment by saying that only self-referential systems create for themselves the possibility of ordering causalities by distribution over system and environment" (1995: 9-10).
} 
Here, relationality is subjected to a radical redefinition, which can be summarized as follows:

a) the constituents of the world (biological, psychic, social) have to be observed and explained through a relational use of the relation in a logical sense; we cannot do without the relation, it is the fabric of everything; in systems based on meaning, the relation practically becomes equivalent to the meaning, or better, the meaning is the relation itself in a logical sense;

b) the theory had to elaborate concepts possessing a "relational capacity"; for instance, the concept of complexity had to be construed in a complex way within itself and this "complex way" meant, above all, the ability to take into account an indefinite number of relations, as well as their component elements; ${ }^{18}$

c) at the same time, "the relationship itself becomes the reduction of complexity, this means however that it must be conceptualized as an emergent system" (Luhmann 1995: 108). In other words, it is the relation (in the logical sense) that both reduces and amplifies complexity;

d) the social relation was no longer the expression of one or more subjects and what they put into their actions; the idea of a reciprocal and mutual action was reduced to communication and only to communication; at the same time, individual people cannot be sure of being understood, because every communication reverberates within self-referential subjectivities that are ever more elusive. It becomes problematic to think of what the unity of a relation could be that would unite a plurality of self-referential systems. Social relations are subjected to a radical temporalization and become circular. The connective sequences they establish become less and less predictable.

With this, functionalism endorses a pervasive "contingentism," which is only mitigated by the pragmatic necessity of the structuring (temporary and sequential) of the "system." This latter appears, ultimately, as a systemic-functional relationality of functional relations. Functionalism, now, is based on quicksand.

\footnotetext{
18 Luhmann says: "Every complex state of affairs is based on a selection of relations among its elements, which it uses to constitute and maintain itself. The selection positions and qualifies elements, although other relations would have been possible" (Luhmann 1995: 25). "One should speak of a reduction in complexity if the framework of relations forming a complex nexus is reconstructed by a second nexus having fewer relations" (Luhmann 1995: 26).
} 
Nevertheless, in the social sciences functionalism remains strong. In spite of his criticisms of Parsons for having underestimated the Lebenswelt, Habermas has ended up re-evaluating a large part of the Parsonian theory positively. Many versions of current alleged relational theories work with a pragmatic functional conception of the social relation as (network) social transactions (Dépelteau \& Powell 2013; Powell \& Dépelteau 2013).

It is possible to see in all of this a confirmation of the fact that, for the current social sciences, systemic-functional analysis is not one approach or a method among the others, but still represents — as it were — the weaving frame of scientific discourse. The greater efficacy of Luhmann's theory in comparison with Habermas's is already evident in the fact that Luhmann has aligned himself not against systemic-functional analysis, but within it and on the same wavelength as it, in order to get a new insight of the postmodern, whereas Habermas has attempted to retrieve it or at least to make it compatible with his normative perspective (the "ideal of modernity").

As both an outlook and a symbolic code, systemic-functional analysis has not only progressively eroded the cultural traditions all over the world, but it has also demonstrated the capacity to regenerate itself continually through more and more sophisticated formulations.

Some believe that cultural traditions are able to recover and to revenge themselves. What hopes do such counter-pressures have to stem the advance of functionalism? It would seem few or none. Functionalism considers them as mere illusions, whilst functional globalization advances almost everywhere. Thus, there is the problem of understanding why and how functionalism, notwithstanding its limitations, continues to be so successful, at least in appearance.

From Durkheim to Parsons, and then to Luhmann, functionalism always takes on new and different guises, but demonstrates a surprising resistance. Many years ago, Alvin Gouldner wrote that functionalism should already be considered dead, and he was not a lone voice. However, this did not happen-why? What is its strength?

A first reason is, without a doubt, the fact that functionalism sets itself apart from value judgments. Theoretically, it assumes a (variable) quantum of epistemological and cultural relativism that implies a certain (variable) degree of (moral) relativism. This is its first strength. Its capacity to be compatible with the most diverse positions is precisely because it does not take a (declared) moral stand, which makes it acceptable to many different approaches. It can also encompass all those concepts and instruments that do not imply taking a stand. 
A second order of reasons is the fact that it is a method that makes use of logical categories with a high power of abstraction. The concept of function, analogous to that of mathematics, allows almost unlimited games, extrapolations, and applications.

In the end, it is clear that functional analysis occupies the same role in sociology as mathematics in economics. Seemingly, it is indispensable. However, mathematics is not everything - not even a way to understand and explain economics - but only a means to make it more calculable and predictable in some respects. The same is true of functional analysis in the social sciences.

My realist relational sociology is precisely an attempt to overcome the shortcomings of functionalism in social science. I contend that social relations are supra-functional; they belong to a supra-functional reality.

Although fascinating, the functionalistic solution leaves open the problem of its relation to the non-functional. The problem of interpretation, which is necessary in order to account for the non-functional, cannot be solved within functional analysis. This is the major deficiency of functionalism, because no functionalist to date has been able to show the human sense of what functionalist analysis puts aside. Social functions are not mechanical mechanisms, but relational mechanisms.

The problem is that functionalism leads to non-functionalism, just as mathematics in economics leads us to acknowledge the existence of what in the economic system is not amenable to mathematical quantification. In exactly the same way, functional analysis cannot cope with the non-functional. How could Luhmann explain free giving, any gratuitous act, or the refusal of communication, the implosion of meaning, the need for justice, the utopia of many social movements and their dynamics? How is it possible, whilst remaining on the terrain of self-referential functionalism, to explain human creativity, the onset of combinatory synergy, the outbreak of a new meaning of things? Are these only new connections activated by causal variability?

The task of excluding/including the non-functional order of reality cannot be solved within functionalism. To solve this problem, it has to be possible to observe the working of the functional principles from a more general viewpoint. This viewpoint is that of relational sociology. For it:

a) meaning has a cultural dimension beyond the material, psychic, and social dimensions; the temporal dimension of meaning traverses and constitutes these four forms of meaning as "other" dimen- 
sions with regard to their contents, whose dynamism is acknowledged (time changes meanings);

b) action is both an intentional act and an emergent;

c) the system is an emergent from a web of relations through processes of morphostasis/morphogenesis;

d) complexity is not synonymous with contingency alone, but is a combination of necessity and contingency, of structure and event;

e) social relations are supra-functional.

Through this more general framing it is perhaps possible to keep the best of functional analysis within a relational analysis that provides a more adequate theory of society.

The solution of the dilemmas unleashed by functionalism does not lie in negating the importance of functional analysis, but in including it into a more general paradigm. The new defining principle becomes the relation. In sociology, observation distinguishes whether an actor, event, structure, or social action "relates or does not relate" and how so.

For the "first functionalism" the equation $y=\mathrm{f}\left(x_{i}\right)$ is valid, where $x_{j}$ are variable factors. For the "second functionalism," $y=\mathrm{f}\left(x_{i}, r_{j}\right)$ is valid, where the relation between factors (that is $r_{j}$ ) is introduced as a further variable. For the "third functionalism," $y=\mathrm{f}\left(x_{i}, r_{j}, r_{n} r\right)$ is valid, where the relationality of relations (that is $\left.r_{n} r\right)^{19}$ is introduced, as a variable.

Relational analysis does not negate the scientific processes that these paradigmatic reformulations have detailed, but instead of " $\mathrm{f}$," it would put a relation " $\mathrm{R}$ " that means a complex reference and also complex bonds that are not necessarily "functional:" i.e., $y=\mathrm{R}\left(x_{j}\right) ; y=\mathrm{R}\left(x_{i}, r_{j}\right) ; y=\mathrm{R}\left(x_{i}, r_{p}, r_{n} r_{j}\right)$. In sociology, the relational operator $\mathrm{R}$ is a social relation whose functions are not distinguishable from the overall meaning they have.

Saying that an entity (even if variable) $y$ (be it a behaviour, a structure, an event, etc.) depends on (is contingent with respect to) other variables $\left(x_{i}\right)$ means to analyse the operator $\mathrm{R}$ that relates them, in a complex and normally supra-functional manner, through relations among elements $(r)$ and relating relations $\left(r_{n} r\right)$. The point is that such relations can be treated as logical only in an abstract formalized way: for the systems formed on the basis of meaning (of a meaning conceptualized as meaningful selection), are primarily cultural patterns interpreted by actors.

19 By "relationality" I mean the reality of "being in relationship," which has a double face: it refers to the fact that the relationship has its own reality (an "act of being," or energeia as Aristotle would call it), and that the two terms which are related (ego and alter) exist in their reciprocal connection (Donati 2015: 96). 
The implication of such change of paradigm can be better understood through an example, i.e., the way I propose to redefine the methodological tool called AGIL, initially put forward by Parsons (who described it in various ways, as a "fourfold model" or as an "interchange model") and used by many other authors (such as Victor Lidz, Jeffrey Alexander, Richard Münch), including Luhmann.

What is AGIL? Here, I wish to specify why and how relational sociology significantly modifies the way the AGIL scheme is conceived. I conceive of AGIL as an instrument for sociological analysis that is useful in analysing social facts as relational and emergent phenomena, rather than as corresponding to a functionalistic logic. Therefore, I reformulate AGIL not only as a scheme for the analysis of social action and of systems of action, but also and above all, as an instrument for the analysis of social relations as emergent phenomena (from which social structures are generated).

\section{/// The Reformulation of the AGIL Scheme in a Relational Version}

In Table 1, I propose a synthesis of the principal versions of AGIL, comparing the theories of Parsons and Luhmann, and my relational theory of society.

In my approach, AGIL is understood as the compass of sociology where the four poles (A-means, G-goals, I-norms, L-values) are the components constituting the social fact as a social relation. Therefore AGIL describes the form of the social relation as a sui generis order of reality emerging from the reciprocal action of agents/actors.

Let us give a couple of examples. First, the love relationship. If we observe a person caring for her dog, we say that she loves her dog. If we observe the same person as a partner in a loving couple with another person, we say that she loves her partner. Each of these love relations are clearly different in their own structure (value, norms, goal, means). Second example, the free giving relationship. Such a relationship can be found in a family, in the initiative of a charity, in the free gift of a gadget by a seller, or a donation to a poor person by a public institution. As in the former case, all these are relations with different structures, although we call them by the same name, i.e., free giving relationships. ${ }^{20}$

AGIL is useful for understanding and explaining in which direction actors and social facts move within social space, conceived here as a "field" in which we observe social subjects, their actions, and relations within

\footnotetext{
20 For more details on how AGIL can be used in analysing free giving see Donati (2003).
} 
a context of social and cultural structures. The term "direction" indicates the "oriented sense" of the social forms emerging in social time and social space. Social structures work through social agents/actors who continually re-orient them through their mediation.

We can pinpoint the differences between the relational approach and those of Parsons and Luhmann. Whereas Parsons's AGIL is tendentiously of a morphostatic nature (within his inertial conception of the social system: Parsons 1951), Luhmann declared that characterization of the social to be dead and buried and saw in AGIL only the autopoietic mechanism through which social systems become the subject of action.

Instead, I conceive of AGIL as a scheme that allows us both to understand and explain social facts as realities that are emergent from the dynamics of social relations, and are therefore the products of social action (and their internal components). The reality of the "social fact" consists in an "emergent effect" which constitutes another stratum of reality, different from those of the elements and the relations between them that have generated it. The social order is the order of the relation. Social structures are nothing other than the stabilization of this relational order during a certain period of time and in a certain space.

The AGIL of relational sociology can capture not only the morphostasis of Parsons, but also the morphogenesis of social relations themselves. Unlike Luhmann's, the relational AGIL is not a mechanical scheme through which to identify the self-differentation of purely self-referential systems, but sees social systems as relational realities which hetero- and selfreferentially constitute themselves in relation to their environment. Every element of the relation-AGIL has its own environment (Donati 2015: 43). I distinguish myself from both Parsons and Luhmann by reformulating AGIL to use it as a compass to understand how social facts emerge from social structures (i.e., the initial AGIL) through interactions among the actors who can modify them to varying degrees, although sometimes not at all. ${ }^{21}$ Finally, AGIL is used to capture both the morphostasis and the morphogenesis of social facts as structures that have to respond to what people make of them. With this, I abandon functionalism, which I consider to be only a method and not a theory.

21 On the inability of both Parsons and Luhmann to explain emergence see D. Elder-Vass (2007). 


\begin{tabular}{|c|c|c|}
\hline T. PARSONS & N. LUHMANN & P. DONATI \\
\hline $\begin{array}{l}\text { 1. It is a scheme to } \\
\text { describe the struc- } \\
\text { ture (synchronic) } \\
\text { of the social action } \\
\text { (unit act) or of a so- } \\
\text { cial structure (insti- } \\
\text { tution) as a system }\end{array}$ & $\begin{array}{l}\text { 1. It is an autopoi- } \\
\text { etic mechanism of } \\
\text { the social system } \\
\text { (the social system is } \\
\text { conceived as com- } \\
\text { munication and } \\
\text { only as communica- } \\
\text { tion) }\end{array}$ & $\begin{array}{l}\text { 1. It is a methodological compass } \\
\text { which serves to orient the investi- } \\
\text { gator in the analysis of the "social } \\
\text { facts" (which are actions, relations } \\
\text { and structures) as emergent phe- } \\
\text { nomena (AGIL captures both the } \\
\text { morphostasis and the morphogen- } \\
\text { esis of the social facts) }\end{array}$ \\
\hline $\begin{array}{l}\text { 2. It consists in four } \\
\text { functions (Adapta- } \\
\text { tion, Goal-attain- } \\
\text { ment, Integration, } \\
\text { Latency) that allow } \\
\text { the system of action } \\
\text { to operate }\end{array}$ & $\begin{array}{l}\text { 2. It consists of two } \\
\text { axes: space (distinc- } \\
\text { tion internal/exter- } \\
\text { nal = I/A) and time } \\
\text { (present/future = } \\
\mathrm{G} / \mathrm{L} \text { ) that operate } \\
\text { as binary distinc- } \\
\text { tions to realize an } \\
\text { indefinite number } \\
\text { of functions (not } \\
\text { only the four func- } \\
\text { tions } A, G, I, L \text { ) }\end{array}$ & $\begin{array}{l}\text { 2. The four poles A,G,I,L are } \\
\text { orientations of meaning (means, } \\
\text { goals, norms, values) of the com- } \\
\text { ponents constituting the social } \\
\text { fact: in particular they are the es- } \\
\text { sential dimensions of the social } \\
\text { relation (AGIL describes the form } \\
\text { of the social relation as a sui generis } \\
\text { order of reality emerging from re- } \\
\text { ciprocal action, which has its own } \\
\text { AGIL) }\end{array}$ \\
\hline $\begin{array}{l}\text { 3. It operates nor- } \\
\text { matively (both } \\
\text { according to the } \\
\text { norms of integra- } \\
\text { tion = function } \\
\text { I and according to } \\
\text { the theorems of } \\
\text { interdependence } \\
\text { and inertia) }\end{array}$ & $\begin{array}{l}\text { 3. The internal/ex- } \\
\text { ternal and present/ } \\
\text { future axis operate } \\
\text { mechanically (that } \\
\text { is without subjec- } \\
\text { tive intention or } \\
\text { value-oriented } \\
\text { norms) }\end{array}$ & $\begin{array}{l}\text { 3. It operates neither in a norma- } \\
\text { tive way (it does not necessarily } \\
\text { follow the norms of Parsons's } \\
\text { I function) nor in mechanical way } \\
\text { (by self-reference and re-entry of } \\
\text { Luhmann's binary distinction), but } \\
\text { works through relationality (AGIL } \\
\text { emerges through relations among } \\
\text { its four dimensions of orientation } \\
\text { and among the relations them- } \\
\text { selves) }\end{array}$ \\
\hline $\begin{array}{l}\text { 4. It is ordered ac- } \\
\text { cording to the cy- } \\
\text { bernetic hierarchy } \\
\text { (maximum control } \\
\text { in } \mathrm{L} \text { that decreases } \\
\text { in } \mathrm{I}, \mathrm{G}, \mathrm{A} \text {; maximum } \\
\text { energy in A that } \\
\text { decreases towards } \\
\mathrm{G}, \mathrm{I}, \mathrm{L} \text { ) }\end{array}$ & $\begin{array}{l}\text { 4. It is ordered ac- } \\
\text { cording to the func- } \\
\text { tional primacy of } \\
\text { one of the possible } \\
\text { functions (i.e., the } \\
\text { functional society is } \\
\text { ordered on the pri- } \\
\text { macy of A, which is } \\
\text { G.O.D. = generator } \\
\text { of diversity) }\end{array}$ & $\begin{array}{l}\text { 4. It does not operate as a cy- } \\
\text { bernetic hierarchy because the } \\
\text { relations among A,G,I,L are mu- } \\
\text { tual actions; it does not operate } \\
\text { mechanically because it emerges } \\
\text { from the interactions between the } \\
\text { actions and relations proper to the } \\
\text { components }\end{array}$ \\
\hline
\end{tabular}

Table 1. Three versions of the AGIL scheme (Parsons, Luhmann, Donati). 


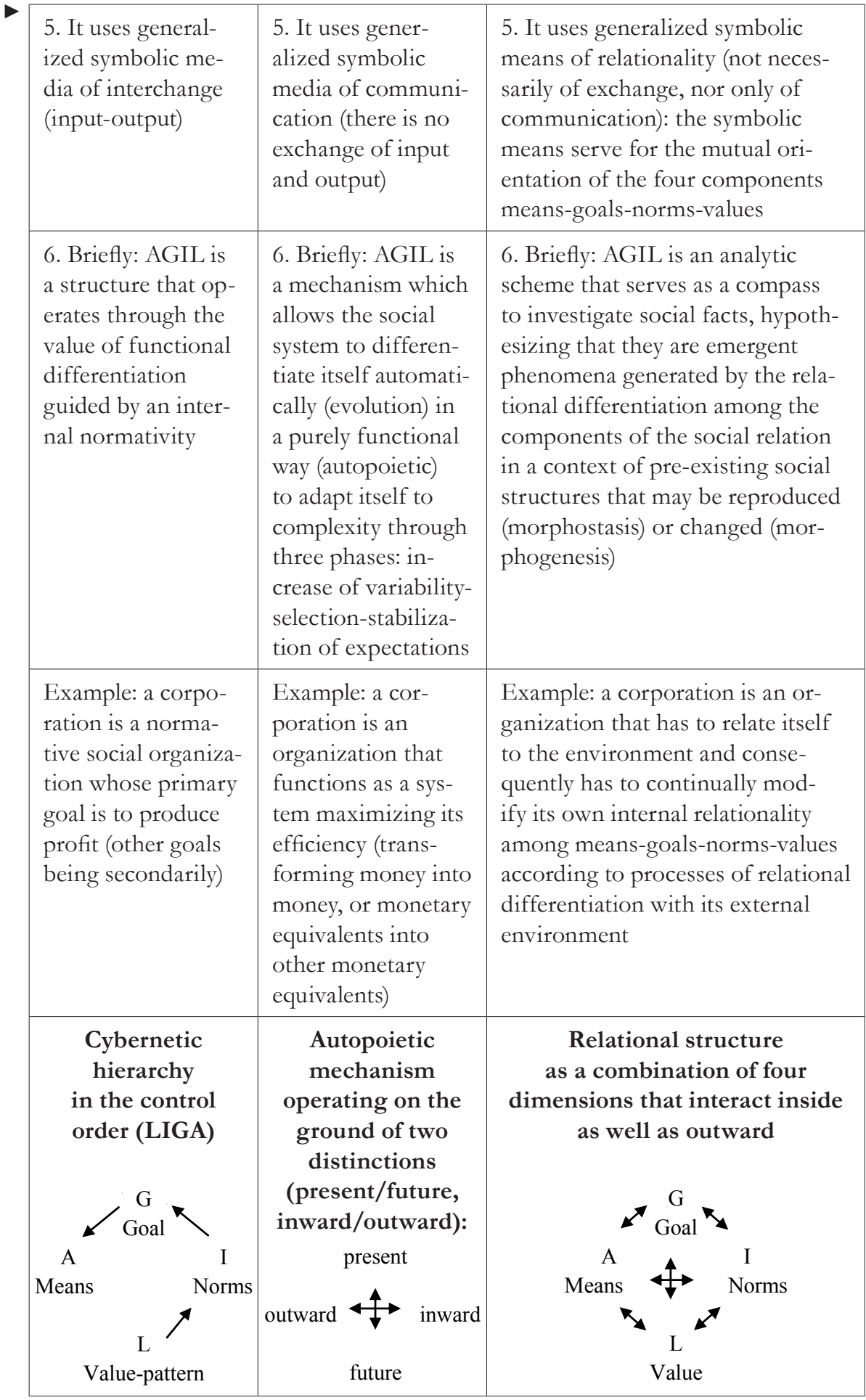


Relational sociology conceives of the AGIL scheme as an analytic tool that retains the four poles A, G, I, L but: first, it interprets them as "orientations of meaning" attributed to these elements or dimensions (constitutive of social phenomena) by the agents/actors who generate and sustain them; second, it stresses the possibilities of relational combinations of these elements/dimensions in a plurality of ways, abandoning the cybernetic hierarchy supposed by Parsons, and clearly criticized by Luhmann.

In empirical reality, the four dimensions of A, G, I, L can all be present or some of them may be absent or in some way inadequate. However, in concrete social dynamics, each of the four dimensions can be a medium or goal or norm or value for the agents involved according to the relations it has with the other three. For instance, money can be a medium or a goal, or a norm or a value according to how it is used and conceived of in the concrete social situation being investigated (money can be the means to buy a dress, the goal of a professional activity, the norm for a banker who wants to transform money into more money, or the monetary value used to establish equivalence between different things). Whether it is one or the other depends on the relations it has with the other dimensions in a given situation. Contrary to functionalism, money does not have an a priori function but can be socially channelled in various ways.

Relational sociology sees the components of AGIL as being relationally generated and, in turn, affecting social relations as such. Relational AGIL describes the form of social relations as a sui generis order of reality (having its own properties and causal powers) that emerges from reciprocal actions (which, in their turn, have their own and different AGILs) (see Donati 2011: 227, Fig. 7.2).

In the relational version, AGIL operates neither in a normative way (it does not necessarily follow the norms of the Parsonian central value system or Luhmann's binary distinctions), but operates by relationality: AGIL emerges through the relations between its four poles or dimensions of orientation and from the relations that exist among these relations. For this reason, society is a relational web of relations.

In the relational version, actions, relations and social systems use the generalized media that are specific to each of the four poles (A, G, I, L), as ones that serve to relate different aspects of actions to each other, to the relation and to the social system. Therefore, the generalized symbolic media are not necessarily exchange media (functional performances according to Parsons) nor are they only media of communication (of information according to Luhmann). The symbolic media serve for the reciprocal orien- 
tation of the four components that constitute action (means-goals-normsvalues). Equally, they serve for the reciprocal orientation of the four social sub-systems (economical system, political system, civil society, families and informal networks) and, within them, for the reciprocal orientation of the various unities that differentiate themselves on the basis of AGIL (which is a recursive acronym, i.e., each dimension of $A, G, I, L$ can be broken down in a sub-AGIL).

The symbolic media enable relational differentiation to be realized. Relational differentiation is distinguished from functional differentiation because it does not operate through specialization of the parts. Instead, it works by enabling meaningful relations to be established between the differentiated parts (which can have specialized functions, but not be entirely separated). In other words, relational differentiation does not follow the fissiparous logic of the division of cells in biology, but follows the social logic of the double contingency inherent in social relations.

Moreover, it is necessary to introduce "relational exchanges," as a new conceptual category in sociology. In the relational AGIL, a type of exchange, termed relational, operates in which the symbolic media are used to actualize a specific type of social relation with its own properties and powers, instead of being a simple "transaction." Let us give some examples of different types of relationships-friendship, doctor-patient, the salepurchase of a house, teacher-student relations-in order to see how in all of these relations some relational exchanges are realized which are not pure symbolic exchange (in which only symbols are transferred) and differ from pure mercantile exchange (in which monetary equivalents are transferred) and also from pure communicational exchange (in which only information is transferred). Relational exchange concerns the bond with other dimensions (symbolic, economic, informative, etc.); a bond that is different for every type of relation. The strength of this bond is, of course, variablefrom very strong to completely absent- but usually it exists to some extent and is characteristic of the empirical AGIL in a concrete situation or social fact. This relational exchange produces a form of differentiation that I call "relational differentiation."

Briefly, for relational sociology, AGIL is an analytic scheme that serves as a compass to investigate the reality of social facts by hypothesizing that they are phenomena emergent from the relational differentiation among the components of the systems of social action, working within the context of social structures. The latter may simply be reproduced (morphostasis) or modified (morphogenesis). Relational AGIL is an instrument with which 
to enter the black box of social processes generating the social fact that the sociologist has to explain and interpret as an "emergent relational effect" (Donati 2006).

It must be underlined that the relational version of AGIL does not claim that there is (or must be) a normative constraint imposing that all the dimensions (A, G, I, L) should be present in all empirical phenomena. On the contrary, what is normal is a lack of such a completeness. The scheme works like a hypothesis against which empirical reality is analysed, by using the same logic of the scientific investigations where empirical frequencies are compared to the expected ones in order to see how the black box works. That is why I represent the relational AGIL as a compass which can tell the researcher in which position the observed factual phenomenon is in respect to the social space (of all possible social configurations) and in which direction it is going when it is observed moving in the course of social time.

Let me give a practical example of how relational sociology makes use of the AGIL scheme in order to understand and explain the relational constitution of the human being.

\section{/// How to Understand the Relational Constitution of the Human Being $^{22}$}

The "after"-modern paradigm for the social sciences that I have outlined here aims at providing an original understanding of the human person as a relational subject whose fulfilment depends on the transcendent world (Donati \& Archer 2015). Human fulfilment is here conceived as the possibility of generating and living relational goods with significant others, as emergent social relations which can be analysed through the relational version of AGIL (Donati 2017). Let me explain this argument, that someone could feel strange or fancy.

I take the moves from the basic work by Margaret Archer (2000) on the human being in which she deals with the vexatious question of how to conceptualize the human being as a living subject from the viewpoint of the social sciences broadly understood. The main difficulty does not consist in seeing what a human person is made of in herself (i.e., the unity

\footnotetext{
22 In my opinion, it is necessary to qualify the person as human (although it seems superfluous) in order to refer to the natural person, because the term "person" may also refer to legal or juridical persons, as is the case with the most sophisticated robots called "electronic persons" (the European Union has approved a document that proposes this recognition to particular robots: recommendations to the Commission on Civil Law Rules on Robotics 2015/2103 INL, May 31, 2016).
} 
of body and mind, the continuity of a "substance" together with its "accidents," etc.), but what relates the human being to the external world and in what way this happens.

Archer claims that the dilemma lies in the circular loop which links the person to society: the person is "both 'child' and 'parent' of society," the generated and the generator at the same time. We need a new scientific paradigm to understand how the human person can be both (a) dependent on society (a supine social product) and (b) autonomous and possessing its own powers (a self-sufficient maker). Classical philosophical thought has coped with this dilemma in a quite simple way: it has reduced the dependence on society to contingency and it has treated autonomy by means of the concept of substance-a solution which refers to a low-complex and "non-relational" society. The idea of classical philosophy, according to which the person is a substance and society is an accidental reality, cannot be sustained any longer if we want to understand the vicissitudes and the destiny of postmodern man.

Relational sociology intervenes here to say that, in what I call the transition to an after-modernity, it is not possible to understand social relations basically as a projection of the human being.

Differently from classical thought, which denies the paradox inherent in the sociality of the human being, modernity accepts it and, more than that, generates it. But the question is: how does modernity solve the paradox, granting that it tries to solve it?

Archer rightly claims that modernity looks for possible solutions by adopting conflationary epistemologies. And in this way modern social sciences lose the human being as such. She is undoubtedly right. So we are left with the task of rescuing the singularity of each human being, his or her dignity and irreducibility, and, at the same time, of seeing the embodiment and embeddedness of the person in social reality without confusing or separating the two faces (singularity and sociality). How can this task be accomplished?

Archer proposes a better conception of the human being, from the perspective of critical realism, which grants humankind (a) temporal priority, (b) relative autonomy, and (c) causal efficacy, in relation to the social beings that they become and the powers of transformative reflection and action which they bring to their social context, powers that are independent of social mediation.

These three operations $(\mathrm{a}, \mathrm{b}, \mathrm{c})$ become likely within a relational theory that, going well beyond modern social sciences, states that: 
- reality is stratified: whichever kind of reality we are observing, it is made up of multiple layers, each one possessing its own powers and emergent properties;

- in-between the layers, there exists a temporal relationality, which means that powers and properties are emergent effects;

- all in all, the relationality of the human being is conceivable as a morphostatic/morphogenetic process.

By adopting this social theory, based upon a realist epistemology (which I call critical, analytical, and relational, without being relationist), it becomes possible to perform some operations which otherwise would be impossible.

a) We can see the pre-social and meta-social reality of the human person, so that the human person cannot be reduced neither to a social product (conflated with society) nor to an idealistic concept.

b) We can observe the identity of the Self, its continuity and its ability to mature within and through social interactions, while it faces the various orders of reality (natural, practical, social) in pursuing its ultimate concerns.

c) We can see how the singularity of the human being is realized in a unique and necessary combination of four orders of reality (natural, practical, social, spiritual or supernatural), so that the contingency turns into a necessity if the person must personalize himself or herself and thus become "more" human.

The challenge of the widespread argument about "the individualization of the individual" is turned into the argument of "the personalization of the person". How? By resorting to the relational constitution of the human person. Let me provide more details.

The first move is to reformulate Archer's fundamental view in the following way. I suggest criss-crossing Archer's scheme concerning the development of the self (Archer 2003: 123-129) with the AGIL scheme as revised in the relational theory of society (Donati 1991: chap. 4) (see Fig. 1).

Standing between the natural world (bio-physical) and transcendence, a human being develops through social interaction. At the start, the person is a subject or potential self ("I") who, through experience (practice), gets out of nature and becomes a primary agent ("Me"), then a corporate agent ("We"), then an actor (auctor) ("You"). To me, it is at this point that the dialectic "I/You" meets the need to cope with the transcendental world. Then the subject returns on to the "I" as a self who, by relating to the 
transcendent world, has given a personal animation to his or her role (the "You") in the immanent world. The exit from nature must always pass through nature again and again. The transcendental reality is treated in the reflexive phase that the subject realizes after having passed through practice and sociality. Through these passages, the subject becomes a more mature self-living in society.

Every mode of being a self (as I, Me, We, You) is a dialogue (an internal conversation) with the subject's "I." The battlefields are everywhere. But I would like to emphasize that they are particularly meaningful (a) at the borders between the "I" and the bio-physical nature, (b) in social interactions, and (c) at the borders with the transcendental world (see Fig. 1). This representation makes clear how the human being can get a progressive divinization (Theosis) while being in the world.

Figure 1 makes it explicit that the "You" can go out of the social and come back to it without living the circle of practice and experience of the world. That is why the personal identity (PI) emerges as distinct from the social identity (SI) exactly because the former is in constant interaction with the latter.

In Archer's view, the latter (SI) is subordinated (i.e., is a sub-set) to the former (PI). I agree with the conceptualization of SI as a subset of PI, provided that it is made clear that "subordination" of SI to PI does not mean that PI can reduce SI identity to itself. SI has its own autonomy in respect to PI, which means that the human being should consider the reasons inherent in social relations as something that the person cannot define and manage in a purely subjective way. Since social relations are entities endowed with their reality, which can be good or bad (to put it bluntly), the "I" needs to take these reasons into consideration and be reflexive on to them. That is why I suggest distinguishing more clearly between personal and relational reflexivity.

Archer defines personal reflexivity as "the regular exercise of the mental ability, shared by all (normal) people, to consider themselves in relation to their (social) contexts and vice versa" (2003: 349). I suggest making more explicit the fact that we should speak of a (different) relational (or social) reflexivity as "the regular exercise of the mental ability, shared by all (normal) people, to consider the influence of their [good or bad] relation(s) with relevant others on to themselves and vice versa." Therefore I suggest distinguishing between those situations in which the SI is subordinated to the PI from those in which there is a veritable interaction between PI and SI, so that the relational constitution of the persons can include the emer- 
gent reality of the social relation and, with it, the Other. Being "relationally reflexive" means being able to reflect on social relations as a reality in itself, since they can represent a relational good or a relational evil (Donati 2011: 192-210) for the person, and therefore, in order to achieve a relational good, he or she must change his or her PI because of the influence exerted by other people on the relations they have together.

Society (which is relationality) is surely a contingent reality, but contingency does not mean pure accident. It is in fact the notion of contingency which is in need of new semantics. Contingency can mean "dependency on" (Parsons), or "the chance not to be, and therefore to be potentially

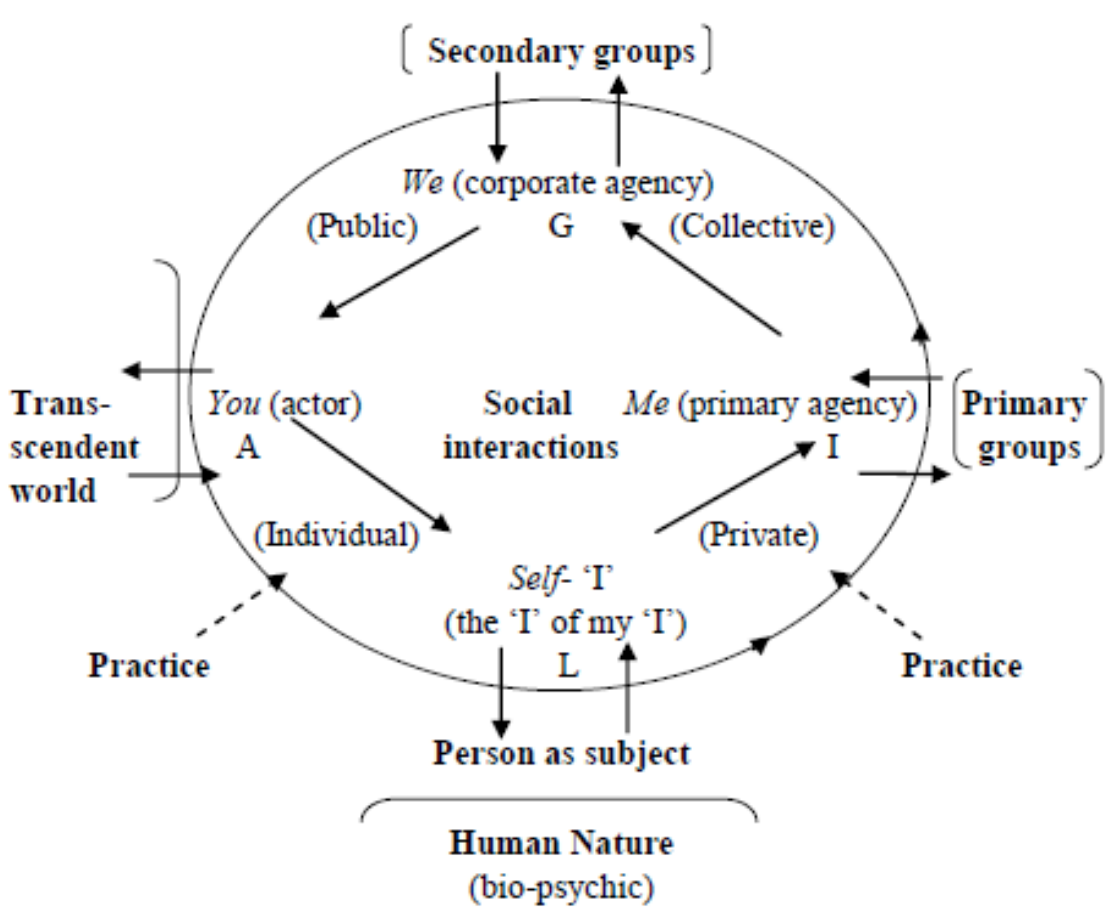

Legenda:

' $T$ '-Subject = person at $T^{1}$ as self (individual-private), having its 'sense of self'

$\mathrm{Me}=$ person at $\mathrm{T}^{2}$ as primary agency (private collective)

$\mathrm{We}=$ person at $\mathrm{T}^{3}$ as corporate agency (collective public)

You $=$ person at $\mathrm{T}^{4}$ as actor (public individual)

The capital letters A,G,I,L correspond to the relational version of AGIL scheme (P. Donati, Teoria relazionale della società, Angeli, Milano, 1991, ch. 4)

Figure 1. The conceptualization of the human being as someone who develops in-between nature, practice, social interaction and transcendence. 
always otherwise" (Luhmann), but it can also mean "the need for personal identity to mature through social identity." The third position implies that contingency can be monitored by the "sense of self," and guided through the internal conversation of the subject, provided that the "I" can accommodate the Self within a relational good. Otherwise, the "I" is caring for what runs the risk of putting the Self within a relational evil.

Without this different semantics of contingency, the human being cannot take the steps that are necessary to go from nature to the supernatural world, discovering its transcendence in respect to society. This is the deepest sense of reflexivity as the proper operation of that internal conversation which makes the human being more human. The social relationality is precisely the fuel or food for the reflexivity, which makes the human being effective.

If we apply the AGIL scheme (in the revised, relational version) to the sequence I-Me-We-You, we can see a quite curious thing: the natural world occupies the dimension of latency $(\mathrm{L})$, while the transcendental world occupies the dimension of adaptation (A). Cultural identities are found within the primary $(\mathrm{I})$ and secondary groups $(\mathrm{G})$ where the person spends his or her life. Why so? My interpretation is that the Self is a latent reality rooted in human nature, while the means (A of AGIL) which realize the human being in society do not consist properly of material instruments, nor of practices as such-not to mention socialization due to social constraints (Durkheim's contrainte sociale, i.e., the pressures of primary and secondary groups with their binding identities), but consist of his or her ultimate concerns.

From this perspective we can better understand the meaning of the statement according to which "who we are is what we care about." Who we are is not a fixed and immovable nature. The human nature exists (in latency L), but its historical dynamics depend on the norms (I) it follows and the goals $(G)$ it pursues, and the latter in turn depends upon the means (A) used to achieve the aims. ${ }^{23}$ To my mind Frankfurt's statement needs a relational explanation and interpretation: it means that our identity as human beings becomes what the "I" can elaborate by reflexively confronting his or her Self with the ultimate concerns he or she de facto relates to, through

\footnotetext{
23 It should be clear that, in my scheme, I am reversing the Parsonian AGIL (where $\mathrm{L}$ is at the border with the ultimate values and A borders with the instrumental conditions of the physical environment). In my scheme, culture is provided by the primary and secondary groups to which a person belongs during her life course.
} 
his or her interactions with primary and secondary social networks during the life span. This is the "economy of human development."

The internal work (reflexivity) of a human being must be accomplished in the dialogue that the "I" has with itself, i.e., when the "I" asks who is really its own "I" when confronted with a "Me" (the identity attributed by the family and informal networks), a "We" (the identity linked to belonging to an association, social movement, organization) and a "You" (the identity actively played as expression of personal autonomy in a social role). In all these moments what is crucial is the confrontation with the ultimate concerns that are involved in a situated context. ${ }^{24}$ In order to operate the distinctions between the different identities, the ultimate concerns (transcending the given conditions) play a fundamental role. When a person asks herself what is "the true 'I' of my 'I'," the person can answer by re-entering a self-referential distinction (as Luhmann thinks), but in this case he or she uses a negative freedom (freedom from constraints) and not a positive freedom (freedom for a good thing) and so does not transcend his or herself. The person can be free and transcend his or herself when he or she chooses which environment to refer to on the basis of a meaningful ultimate concern (which is a relational operation where self-reference and hetero-reference are accomplished jointly by the person). When discussing with his or herself and deciding where to bring the "I," one self has to be both self-referent and hetero-referent (this is where "the social" - the relational constitution of the human person-comes into play).

Many questions, of course, are left open. With reference to my Figure 1, we can envisage the following open issues. They lie (a) at the borders between nature and the person in society, (b) in the relationships between the internal reflexivity of the person and its social networks, and (c) at the boundaries between the human being and transcendence.

a) The border between nature and the person in society (the battlefield of practical experience) becomes more and more problematic in so far as society changes nature continuously. Certainly, nature reacts. But changes produced by science and technology are challenging the ability of the human being to dialogue with nature at its very roots. The question is: will the subject be able to relate itself to nature when society would make nature

\footnotetext{
24 In this sense, I am suggesting the revision of the approach by E. Goffman (1988), who talks of the priority of the "moments over the persons." In his approach, when acting in social interactions, human beings follow rituals and play games, whilst in my view they confront themselves (their identities) reflexively. This means that they ask their Self which is their ultimate (transcendent) concern and therefore which situated goals they can pursue and which norms can actually be put in practice.
} 
more and more unrecognizable and indistinct? It is evident that changes in the natural world can shift the thresholds within which the experience of the "sense of self" can be adequately managed.

b) The second question concerns the relation between the internal reflexivity of the person and the social networks he or she belongs to. If the person is an emergent (Smith 2010), the argument of the ontological and epistemological impossibility of the reduction of the emergent state is determined by the constitutive feature of consciousness, namely, reflexivity. However, the emphasis on the internal reflexivity of the human being needs to be connected to the properties and powers of the social networks in which people live. Since these networks may have their own "reflexivity" (of a different kind), much remains to understand about the interactions between the inner conversation of the person and the reflexivity of the network to which he or she belongs.

c) The third set of questions concerns the borders between the person and the transcendental world. The ability of the human being to connect him or herself to the transcendental world strongly depends on his or her ability to "symbolize," i.e., to understand and appropriate the symbolic world (to know reality through symbols). The question is: how is this ability produced in the internal conversation? How is it promoted or endangered by society? Certainly, we must distinguish between different types of symbols: prelinguistic, linguistic, and "appresentative" (in the phenomenological sense). But it seems to me that much effort should be made to understand the importance of symbols — their formation and their use-in getting a person properly involved in the supernatural world. My feeling is that sociology has reduced the symbols to what sociologists call the "media," i.e., the generalized media of interchange according to Parsons and the generalized means of communication according to Luhmann. It is evident that symbols cannot be reduced to exchange or communicative means when dealing with the transcendent world. These "symbolic means" are to be understood as relations to another order of meta-reality (Bhaskar 2012), or to what I call a theological matrix of society (Donati 2010).

To conclude: the emergentist paradigm of the human being puts the old query of the relation between personal identity and social identity in new terms.

While most sociologies observe the relation "Personal Identity (PI) $\leftrightarrow$ Social Identity (SI)" as an antithesis, relational sociology conceives of it as an interactive elaboration which develops over time, provided that the 
personal identity side operates it. It can induce humanization only by being asymmetric.

We can therefore go well beyond those scholars who, in the last century, thought of the relation between PI and SI as something necessarily reifying the human being, or making it liquid or fragmented and divided against itself, on the basis of an alleged dualism between the human and the social. The human being must deal with all kinds of social relations. We need not oppose system relations (system integration) and life-world relations (social integration), good and bad relations in themselves, in so far as what is relevant is the reflexivity of the human being in dealing with them, i.e., in coping with relationally contested contexts.

Only this vision can explain why and how the human being can emerge from social interactions, while he or she precedes and goes beyond society. In short, the relation between PI and SI is a dialogue between the life-world (intersubjective relations) and social institutions (role relations), but it must not be conceived as symmetric, because it is acted by the subject (agent and actor) who does not want simply to animate a role, but also to personify it in a singular manner.

This vision, proper to critical realism, allows us to give room to, to think of, and to promote the capabilities of the human being to forge a more human society, notwithstanding the fact that modernity has brought us into an anti-human era. Such a view is grounded on the idea, supported by empirical research, that human fulfilment does not rest primarily on natural, physical, or material means, but on those ultimate concerns that fuel proper social relations.

\section{/// Relationality as the Game of Games}

For many sociologists, action-oriented knowledge remains a way of observing or studying relations between "actors" and "facts"—or even between "variables"- such as action, power, money, and class-rather than a way of observing or studying social phenomena as relations or, better still, as relations of relations. Starting from this position, they end up collapsing into relativism (relationism) and thus undermining the very analysis of social relations.

One can say that even where sociology has developed relational thinking, this has often had an idealist or positivist character, but has rarely been realist in the sense of critical, relational realism. This kind of realism is committed to an understanding and explanation of the social world that 
neither reifies nor subjectifies it, but sees it as objective in so far as it is previously established with respect to the actors/agents, is constructed in the here and now, and acquires a conditioning reality that rests on a meta-level with respect to the subjective perceptions of the people involved.

In any case, from simply appreciating epistemologically that any object of study is socially constructed, one cannot—and should not-conclude that it is only a social product, since reality is stratified at different levels and is a creation in which the natural, social, practical and transcendental worlds mingle and play with each other relationally. To reduce social relations only at the level of communications or functional performances leads to unjustifiable forms of sociologism. In order to get a properly reflexive capacity to critically observe what sociology is construing in/by itself and what "is out there" as a reality in itself, we need an adequate relational epistemology (an observing system that is not purely self-referential, if one wishes to use this language).

In the social sciences, the subject of action cannot be observed, understood or explained in and of itself, except through —inside of, with, and by means of-social relations. The postmodern relationism can only be transcended through a careful and comprehensive reading of social relations, one that is multidimensional and supra-functional, in short-relational. Through social relations, the human subject is, or can be seen again as, a meaningful agent, as the normative source of the relation, given that action is normative in so far as it entails interpretation. To claim that action is normative means that it necessarily requires an interpretation of meanings, and in that sense is "hermeneutic," but one should never forget that social relations exceed the will and the subjective meaning of the actors.

At the end of this paper, I summarize in Table 2 the main differences between what I call relationist and relational sociology.

What we want to know are the social facts in so far as they are real. But we cannot know them other than in and through relations.

a) The relation is the key to enter into social reality and to come out of it (in so far as knowledge is a relation used by an observer who wants to get into what is observed - insight, involvement-and come out of it-detachment).

b) The relation does not eliminate the elements that it connects, but rather calls upon them, explores, and expresses them.

c) The relation is not a pure abstraction (a pure form or communication) but is a "concrete." 


\begin{tabular}{|l|l|}
\hline $\begin{array}{l}\text { Relationist sociology } \\
\text { (M. Emirbayer) }\end{array}$ & $\begin{array}{l}\text { Relational sociology } \\
\text { (P. Donati) }\end{array}$ \\
\hline $\begin{array}{l}\text { Does not see the social relation } \\
\text { as an emergent }\end{array}$ & $\begin{array}{l}\text { Sees the social relation } \\
\text { as an emergent reality }\end{array}$ \\
\hline $\begin{array}{l}\text { Claims that relations generate struc- } \\
\text { tures that have no proper causal power }\end{array}$ & $\begin{array}{l}\text { Claims that relations (as emergent } \\
\text { structures) have peculiar causal powers }\end{array}$ \\
\hline $\begin{array}{l}\text { Conceives of the Self as entirely rela- } \\
\text { tionistic because it is not considered } \\
\text { as a locus of free choice and agency } \\
\text { due to the fact that it is defined by the } \\
\text { relational process, as a transaction or } \\
\text { a form of communication }\end{array}$ & $\begin{array}{l}\text { Conceives of the Self as relational in } \\
\text { the sense that it is viewed as a locus } \\
\text { of free choice and agency in relation } \\
\text { to an alter by knowing or interpreting } \\
\text { its concerns through the behaviours } \\
\text { and choices made by the alter in a rela- } \\
\text { tional context }\end{array}$ \\
\hline
\end{tabular}

Table 2. Comparing relationist and relational sociologies.

d) It follows that such a relational entity (emergent), encompassing human thoughts, can be dichotomous or dual only under extreme circumstances; normally, it has a network structure that connects, bonds, and creates interdependencies, along with associated tensions and conflicts.

e) Norms and rules are a necessary and inevitable way of regulating, under normal conditions, the contingency of situations that are not socially predetermined.

In short, the relation, not duality or absolute ambivalence or anything else, is the supreme game of games. But the social relation is not a pure game. One cannot say of it what Wittgenstein (1979) said of the linguistic game in his essay On Certainty: "Something unforeseeable... I mean it is not founded, it is not rational, or irrational. It is just there like our life..." That social relations follow vague, fuzzy, or ambiguous rules, forms part of our common everyday experience, as does our tendency to polarize- to think in binary codes: inside-outside, symmetric-asymmetric, which is the easiest way of simplifying reality. But social relations cannot be structurally uncertain, ambiguous, or dichotomous in the long run. Passing through the different temporal phases and their outcomes, relationships take on a structure, which changes along time cycles. Their task is to go beyond ambiguity and dichotomy even if they continuously generate these conditions. 
Bibliography:

/// Alexander J.C. 1996. Fin de Siècle Social Theory : Relativism, Reduction, and the Problem of Reason, Verso.

/// Archer M. 2000. Being Human: The Problem of Agency, Cambridge University Press.

/// Archer M. 2003. Structure, Agency and the Internal Conversation, Cambridge University Press.

/// Archer M. 2012. The Reflexive Imperative in Late Modernity, Cambridge University Press.

/// Archer M., ed. 2014. Late Modernity: Trajectories towards Morphogenic Society, Springer.

/// Ardigò A. 1988. Per una sociologia oltre il post-moderno, Laterza.

/// Bhaskar R. 1979. The Possibility of Naturalism: A Philosophical Critique of the Contemporary Human Sciences, The Harvester Press.

/// Bhaskar R. 2012. Reflections on MetaReality: Transcendence, Emancipation and Everyday Life, Routledge.

/// Blau P. 1982. Structural Sociology and Network Analysis, [in:] Social Structure and Network. Analysis, eds. P. Marsden, N. Lin, Sage Publications, pp. 273280.

/// Brint S. 2005. Guide for the Perplexed: On Michael Burawoy's "Public Sociology”, “The American Sociologist”, vol. 36(3-4), pp. 46-65.

/// Buch-Hansen H. 2013. Social Network. Analysis and Critical Realism, "Journal for the Theory of Social Behaviour", vol. 44(3), pp. 306-325.

/// Buckley W. 1967. Sociology and Modern Systems Theory, Prentice Hall.

/// Cook W.L., Dreyer A. 1984. The Social Relations Models, "Journal of Marriage and Family", vol. 46(3), pp. 679-687.

/// Davis K. 1959. The Myth of Functional Analysis as a Special Method in Sociology and Anthropology, "American Sociological Review", vol. 24(6), pp. 757-772.

/// Dépelteau F., Powell C., eds. 2013. Applying Relational Sociology: Relations, Networks, and Society, Palgrave Macmillan. 
/// Donati P. 1983. Introduzione alla sociologia relazionale, FrancoAngeli. [Second enlarged edition 1986.$]$

/// Donati P. 1991. Teoria relazionale della società, FrancoAngeli.

/// Donati P. 2003. Giving and Social Relations: The Culture of Free Giving and its Differentiation Today, "International Review of Sociology", vol. 13(2), pp. 243-272.

/// Donati P. 2006. L'analisi relazionale: regole, quadro metodologico, esempi, [in:] Sociologia. Una introdurione allo studio della società, ed. P. Donati, Cedam, pp. 213-227.

/// Donati P. 2009. La società dell'umano, Marietti.

/// Donati P. 2010. La matrice teologica della società, Rubbettino.

/// Donati P. 2011. Relational Sociology: A New Paradigm for the Social Sciences, Routledge.

/// Donati P. 2013. Morphogenesis and Social Networks: Relational Steering not Mechanical Feedback, [in:] Social Morphogenesis, ed. M.S. Archer, Springer, pp. 205-231.

/// Donati P. 2015. L'enigma della relazione, Mimesis Edizioni.

/// Donati P. 2017. What Does a 'Good Life' Mean in a Morphogenic Society? The Viewpoint of Relational Sociology, [in:] Morphogenesis and Human Flourishing, ed. M.S. Archer, Springer, pp. 137-161.

/// Donati P., Archer M. 2015. The Relational Subject, Cambridge University Press.

/// Durkheim É. 1982. The Rules of Sociological Method, Macmillan Press.

/// Durkheim É. 1984. The Division of Labour in Society, Macmillan Press.

/// Elder-Vass D. 2007. Luhmann and Emergentism: Competing Paradigms for Social Systems Theory?, "Philosophy of the Social Sciences", vol. 37(4), pp. 408-432.

/// Emirbayer M. 1997. Manifesto for a Relational Sociology, "American Journal of Sociology", vol. 103(2), pp. 281-317.

/// Etxeberria A. 2004. Autopoiesis and Natural Drift: Genetic Information, Reproduction, and Evolution Revisited, "Artificial Life", vol. 10(3), pp. 347-360. 
/// von Foerster H. 1984. Observing Systems, Intersystems Publications.

/// Fuhse J. 2009. The Meaning Structure of Social Networks, "Sociological Theory", vol. 27(1), pp. 51-73.

/// Geertz C. 1973. Thick Description: Toward an Interpretive Theory of Culture, [in:] C. Geertz, The Interpretation of Cultures: Selected Essays, Basic Books, pp. $3-30$.

/// Goffman E. 1988. Les moments et leurs hommes, Seuil.

/// Hałas E. 1991. Images of Man in Symbolic Interactionism and the Problem of Homo Aestimans, “The Polish Sociological Bulletin”, vol. 1, pp. 51-61.

/// Hałas E. 2016. Through Social Values to the Reinterpretation of Sociology's Ethical Neutrality, "Sociologia e Politiche Sociali", vol. 19(1), pp. 67-79.

/// Huston T., Robins E. 1982. Conceptual and Methodological Issues in Studying Close Relationships, "Journal of Marriage and the Family", vol. 44(4), pp. 901-925.

/// Laumann E., Marsden P., Prensky D. 1983. The Boundary Specification Problem in Network Analysis, [in:] Applied Network Analysis, eds. R. Burt, M. Minor, Sage Publications, pp. 18-34.

/// Luhmann N. 1988. Soz̧ialsystem Familie, "System Familie", vol. 1, pp. 75-91.

/// Luhmann N. 1995. Social Systems, Stanford University Press.

/// Maruyama M. 1963. The Second Cybernetics: Deviation-Amplifying Mutual Causal Processes, "American Scientist”, vol. 51, pp. 164-179.

/// Merton R.K. 1968. Social Theory and Social Structure, Free Press.

/// Morandi E. 2010. Introductory Outlines to Pierpaolo Donati's Relational Sociology: Part 1, "Journal of Critical Realism”, vol. 9(2), pp. 208-226.

/// Morandi E. 2011. Introductory Outlines to Pierpaolo Donati's Relational Sociology: Part 2, "Journal of Critical Realism", vol. 10(1), pp. 100-121.

/// Parsons T. 1951. The Social System, Free Press.

/// Powell C., Dépelteau F., eds. 2013. Relational Sociology. Ontological and Theoretical Issues, Palgrave Macmillan.

/// Rorty R. 1999. Philosophy and Social Hope, Penguin Books. 
/// Sim M. 2003. The Moral Self in Confucius and Aristotle, "International Philosophical Quarterly", vol. 43(4), pp. 439-462.

/// Smith C. 2010. What is a Person? Rethinking Humanity, Social Life, and the Moral Good from the Person Up, University of Chicago Press.

/// Tam T. 1989. Demarcating the Boundaries between Self and the Social: the Anatomy of Centrality in Social Networks, "Social Networks", vol. 11(4), pp. 387-401.

/// Terenzi P., Boccacin L., Prandini R., eds. 2016. Lessico della sociologia relazionale [Lexicon of Relational Sociology], il Mulino.

/// Toulemont R. 1962. L'essence de la société selon Husserl, Puf.

/// Wittgenstein L. 1979. On Certainty, Basil Blackwell.

\section{/// Abstract}

The paper presents a general outline of the author's relational sociology, showing it to be different from other relational sociologies, which are, in fact, figurational, transactional, or purely communicative. Relational sociology is conceived as a way of observing and thinking that starts from the assumption that the problems of society are generated by social relations and aims to understand, and if possible, solve them, not purely on the basis of individual or voluntary actions, nor conversely, purely through collective or structural ones, but via new configurations of social relations. The social is relational in essence. Social facts can be understood and explained by assuming that "in the beginning (of any social fact there) is the relation." Ultimately, this approach points to the possibility of highlighting those relational processes that can better realize the humanity of social agents and give them, as relational subjects, the opportunity to achieve a good life in a society that is becoming increasingly complex as the processes of globalization proceed.

Keywords:

relational sociology, relationist sociology, relational subject, social morphogenesis, human person 
/// Pierpaolo Donati-Alma Mater professor of sociology at the University of Bologna (Italy). Formerly president of the Italian Sociological Association, he has served as a counsellor on the board of the International Institute of Sociology. At present he belongs to the Pontifical Academy of Social Sciences and the Academy of Sciences of the University of Bologna. He is known as the "founding father" of Italian relational sociology, also called the "relational theory of society," which he has expounded in around 800 publications. Recent works include: Relational Sociology: A New Paradigm for the Social Sciences (2011) and The Relational Subject (with M.S. Archer, 2015). E-mail: pierpaolo.donati@unibo.it 